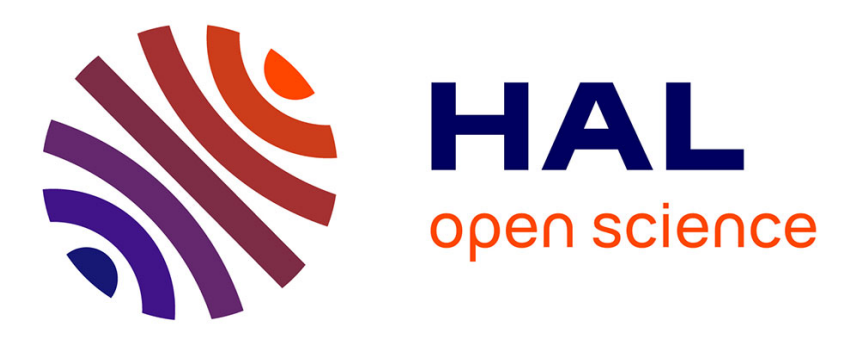

\title{
The tensile strength of volcanic rocks: Experiments and models
}

\author{
Michael J Heap, Fabian B Wadsworth, Zhen Heng, Tao Xu, Luke Griffiths, \\ Andrea Aguilar Velasco, Emma Vairé, Marie Vistour, Valentin R Troll, \\ Frances M Deegan, et al.
}

\section{To cite this version:}

Michael J Heap, Fabian B Wadsworth, Zhen Heng, Tao Xu, Luke Griffiths, et al.. The tensile strength of volcanic rocks: Experiments and models. Journal of Volcanology and Geothermal Research, 2021, 418, pp.107348. 10.1016/j.jvolgeores.2021.107348 . hal-03419667

\section{HAL Id: hal-03419667 https://hal.science/hal-03419667}

Submitted on 8 Nov 2021

HAL is a multi-disciplinary open access archive for the deposit and dissemination of scientific research documents, whether they are published or not. The documents may come from teaching and research institutions in France or abroad, or from public or private research centers.
L'archive ouverte pluridisciplinaire HAL, est destinée au dépôt et à la diffusion de documents scientifiques de niveau recherche, publiés ou non, émanant des établissements d'enseignement et de recherche français ou étrangers, des laboratoires publics ou privés. 
1 The tensile strength of volcanic rocks: Experiments and models

3 Michael J. Heap ${ }^{1,2 *}$, Fabian B. Wadsworth ${ }^{3}$, Zhen Heng ${ }^{4}$, Tao $\mathrm{Xu}^{4}$, Luke Griffiths ${ }^{5}$,

4 Andrea Aguilar Velasco ${ }^{1}$, Emma Vairé ${ }^{1}$, Marie Vistour ${ }^{1}$, Thierry Reuschlé1, Valentin R.

5 Troll $^{6}$, Frances M. Deegan ${ }^{6}$, and Chun'an Tang ${ }^{7,8}$

6

${ }^{1}$ Université de Strasbourg, CNRS, Institut Terre et Environnement de Strasbourg, UMR 7063,

5 rue René Descartes, Strasbourg F-67084, France

$9 \quad{ }^{2}$ Institut Universitaire de France (IUF), 1 rue Descartes, Paris 75231, France

$10 \quad{ }^{3}$ Earth Science, Durham University, Science Labs, Durham, DL1 3LE, United Kingdom

$11{ }^{4}$ Center for Rock Instability and Seismicity Research, Northeastern University, Shenyang

110819, China

${ }^{5}$ NGI - Norwegian Geotechnical Institute, Oslo, 0806, Norway

${ }^{6}$ Department of Earth Sciences, Natural Resources and Sustainable Development (NRHU),

Uppsala University, Uppsala, Sweden

${ }^{7}$ State Key Laboratory of Coastal \& Offshore Engineering, Dalian University of Technology,

Dalian, 116024, China

${ }^{8}$ State Key Laboratory of Geological Processes and Mineral Resources, China University of

19 Geosciences (Wuhan), Wuhan, 430074, China

*Corresponding author: Michael Heap (heap@unistra.fr)

\section{Abstract}

The tensile strength of volcanic rock exerts control over several key volcanic processes, including fragmentation and magma chamber rupture. Despite its importance, there is a paucity 
of laboratory data for the tensile strength of volcanic rocks, leading to an incomplete understanding of the influence of microstructural parameters, such as pore size and shape (factors that vary widely for volcanic rocks), on their tensile strength. To circumvent problems associated with the variability of natural samples, we provide here a systematic study in which we use elastic damage mechanics code "Rock Failure Process Analysis" to perform numerical experiments to better understand the influence of porosity, pore diameter, pore aspect ratio, and pore orientation on the tensile strength of volcanic rocks. We find that porosity and pore diameter exert a first-order control on the tensile strength of volcanic rocks, and that pore aspect ratio and orientation also influence tensile strength. Tensile strength is reduced by up to a factor of two as porosity is increased from 0.05 to 0.35 or as pore diameter is increased from 1 to 2 $\mathrm{mm}$. Small, but systematic, reductions in tensile strength are observed as the angle between the loading direction and the major axis of an elliptical pore is increased from 0 to $90^{\circ}$. The influence of pore aspect ratio (the ratio of the minor to major axis of an ellipse) depends on the pore angle: when the pore angle is $0^{\circ}$, a decrease in pore aspect ratio, from 1 (a circle) to 0.2 , increases the tensile strength, whereas the same decrease in pore aspect ratio does not substantially change the tensile strength when the pore angle is $90^{\circ}$. These latter numerical experiments show that the tensile strength of volcanic rocks can be anisotropic. Our numerical data are in broad agreement with new and compiled experimental data for the tensile strength of volcanic rocks. One of the goals of this contribution is to provide better constrained constitutive models for the tensile strength of volcanic rocks for use in volcano modelling. To this end, we present a series of theoretical and semi-empirical constitutive models that can be used to determine the tensile strength of volcanic rocks, and highlight how tensile strength estimations can influence predictions of magma overpressures and assessments of the volume and radius of a magma chamber. 
Key words: Tensile strength; volcanic rock; porosity; pore geometry; constitutive models

\section{Introduction}

Volcanoes and volcanic rocks are pervasively fractured at a variety of scales, and the abundance of tensile (opening-mode) fractures observed in volcanic systems speaks to the importance of the tensile strength of volcanic rocks. For example, thermal stresses can create tensile fractures on the microscale (e.g., Browning et al., 2016; Daoud et al., 2020) and the macroscale (e.g., Aydin and DeGraff, 1988; Lamur et al., 2018), the shearing of magma can create en échelon tensile fractures (e.g., Kushnir et al., 2017), and pressurised pore fluids can create hydrofractures and tuffisites (e.g., Heiken et al., 1988; Tuffen et al., 2003; Heap et al., 2019a).

The tensile strength of volcanic rocks is an important input parameter for volcano modelling (e.g., see discussion in Heap and Violay, 2021). For example, magma pressures must exceed the tensile strength of the host rock in order to propagate dykes to feed eruptions (e.g., Gudmundsson, 2006) and, therefore, the tensile strength of volcanic rocks is an important parameter in eruption forecasting (e.g., Gudmundsson, 2006; Browning et al., 2015; Zhan and Gregg, 2019). The tensile strength of volcanic rocks is also required in some volcano deformation models (e.g., Holohan et al., 2011) and as an input parameter in some discrete element method (DEM) models designed to understand dome growth and behaviour (e.g., Harnett et al., 2018; Walter et al., 2019). Finally, tensile strength also controls the fragmentation of volcanic rocks and magmas (e.g., Alidibirov, 1994; Spieler et al., 2004; Koyaguchi et al., 2008).

Experimental studies have shown that the tensile strength of volcanic rocks decreases as a function of porosity (e.g., Heap et al., 2012; Lamb et al., 2017; Hornby et al., 2019; Harnett et al., 2019; Kendrick et al., 2021; Heap and Violay, 2021). For example, Harnett et al. (2019) 
found that the tensile strength of andesites from Soufrière Hills volcano (Montserrat) was reduced from $\sim 4$ to $\sim 0.5 \mathrm{MPa}$ as porosity increased from $\sim 0.22$ to $\sim 0.4$. The tensile strength of dacite from Mt Unzen volcano was reduced from $\sim 5.75 \mathrm{MPa}$ at a porosity of $\sim 0.03$ to $\sim 1.8 \mathrm{MPa}$ at a porosity of $\sim 0.35$ (Hornby et al., 2019; Kendrick et al., 2021). However, although studies have shown that pore size, shape, and orientation influence the compressive strength of volcanic rock (e.g., Heap et al., 2014a; Bubeck et al., 2016; Griffiths et al., 2017), systematic studies on the influence of these microstructural attributes on the tensile strength of volcanic rocks are currently unavailable. Understanding the effect of pore size, pore shape, and pore orientation on the tensile strength of volcanic rocks is important due to (1) the above-outlined importance of tensile strength for volcanic systems and modelling, (2) the tremendous diversity of pore geometry observed in volcanic rocks, which can also be characterised by a preferred pore shape orientation (anisotropy) (e.g., Wright et al., 2009; Shea et al., 2010; Voltolini et al., 2011), and (3) the large influence these parameters exert on the compressive strength of volcanic rocks (Heap et al., 2014a; Bubeck et al., 2016; Griffiths et al., 2017).

We present here a study in which we systematically explore the influence of porosity, pore size, pore aspect ratio, and pore orientation on the tensile strength of volcanic rocks. We performed numerical experiments to circumvent the problems associated with natural sampleto-sample variability, and the difficulty in finding suites of volcanic rocks in which only one microstructural parameter varies whilst the others remain constant. These numerical experiments, based on elastic damage mechanics, allow us to vary one parameter at a time and therefore investigate the influence of each parameter in isolation. We then compare the results of these numerical experiments with laboratory data (both unique to this study and compiled from the literature). Finally, we present a series of theoretical and semi-empirical constitutive models that can be used to estimate the tensile strength of volcanic rocks. We then outline the relevance of our results for volcano modelling. Although the input parameters for our numerical 
101

102

103

104

105

106

107

108

109

110

111

112

113

114

115

116

experiments are calibrated for volcanic rocks, we highlight that the salient conclusions of this study are likely relevant for a wide range of rock types, not just volcanic rocks.

\section{Materials and methods}

\subsection{Numerical samples and experiments}

The numerical samples were generated using a 2D version of a "hard-sphere" algorithm in which circles or ellipses ("pores") are randomly generated in an aperiodic 2D domain ("groundmass"), with the requirement of no-overlap with each other. This algorithm was implemented in Python ${ }^{\mathrm{TM}}$. The numerical samples are circular bitmap images that are 375 pixels in diameter. At a resolution of 7.5 pixels $/ \mathrm{mm}$, the circular samples are $50 \mathrm{~mm}$ in diameter (the assignment of a resolution is discussed below). Three sets of samples were generated in which varied combinations of porosity, $\phi$, pore radius (for circular pores), $r$, pore orientation, $\theta$, and pore aspect ratio (for elliptical pores), $r_{a} / r_{b}$, where $r_{a}$ and $r_{b}$ are the minor to major semi axis of an ellipse, respectively (Table 1).

(1) Samples containing circular pores (aspect ratio of 1) were generated to contain porosities, $\phi$, of $0.02,0.05,0.1,0.15,0.2,0.25,0.3$, and 0.35 , with a pore diameter, $2 r$, of either $1,1.5$, or $2 \mathrm{~mm}$. Two samples were generated for each combination of porosity and pore size, resulting in a total of 48 samples (Table 1).

(2) Samples containing a porosity, $\phi$, of 0.1 and a pore aspect ratio, $r_{a} / r_{b}$, of 0.5 were generated such that their pore angles (the angle between the loading direction and the major axis of the elliptical pore), $\theta$, were $0,10,20,30,40,50,60,70,80$, and $90^{\circ}$. The major semi axis, $r_{b}$, in these samples was fixed at $1 \mathrm{~mm}$. Two samples were generated for each angle, resulting in a total of 20 samples (Table 1).

(3) Samples containing a porosity, $\phi$, of 0.1 were generated with pore angles, $\theta$, of 0 , 45 , or $90^{\circ}$ and pore aspect ratios, $r_{a} / r_{b}$, of $0.2,0.25,0.33,0.5$, and 0.67 (for a fixed 
$r_{b}$ of $1 \mathrm{~mm}$ ). Two samples were generated for each combination of pore angle and pore aspect ratio, resulting in a total of 30 samples (Table 1).

128 We generated a total of 98 numerical samples, examples of which are shown in Figure 1.

129 Although our numerical samples greatly simplify the microstructural complexity of natural

130 volcanic rocks, in simplifying the microstructure of our numerical samples (pores that are either

131 circles or ellipses) we are able to better understand the influence of individual microstructural

132 parameters on tensile strength. We can also calculate the pore number density, $N$, for each of

133 our numerical samples, where $N=\phi /\left[(1-\phi) A_{i}\right] . A_{i}$ represents the area of one of the pores

134 in the domain so that $A_{i}=\pi r_{a} r_{b}$, where $r_{a}=r_{b} \equiv r$ for circular pores. Therefore, across our

135 numerical experiments, we cover $6.50 \times 10^{3} \leq N \leq 6.86 \times 10^{5} \mathrm{~m}^{-2}$. We note that in our system,

$136 N$ is an areal number density, a 2D equivalent to the $3 \mathrm{D}$ volumetric number density. We find

137 that, for our numerical samples, $N$ increases and decreases as porosity and pore diameter

138 increase, respectively. We note that the pore diameters used in the numerical experiments (1-2

$139 \mathrm{~mm}$; Table 1) are larger than the pore diameters observed in the experimental samples (see

140 Section 2.2 below). The minimum size of a circular pore is a function of the pixel or element

141 size (the resolution of our numerical samples is 7.5 pixels $/ \mathrm{mm}$ ). Pore sizes of $1-2 \mathrm{~mm}$ allowed

142 us to prepare numerical samples containing not only circular pores, but also samples in which

143 we could vary the pore aspect ratio and pore angle (Table 1).

\begin{tabular}{|c|c|c|c|c|}
\hline Porosity & $\begin{array}{c}\text { Pore diameter } \\
\text { (circle), } 2 \boldsymbol{r}, \text { or } \\
\text { major axis } \\
\text { diameter, } 2 \boldsymbol{r}_{\boldsymbol{b}} \\
\text { (ellipse) } \\
(\mathbf{m m})\end{array}$ & $\begin{array}{c}\text { Pore angle, } \boldsymbol{\theta} \\
\left(^{\circ}\right)\end{array}$ & $\begin{array}{c}\text { Pore aspect } \\
\text { ratio, } \boldsymbol{r}_{\boldsymbol{a}} / \boldsymbol{r}_{\boldsymbol{b}}\end{array}$ & $\begin{array}{c}\text { Number of } \\
\text { numerical } \\
\text { samples }\end{array}$ \\
\hline 0.1 & $1,1.5,2$ & - & 1 & 48 \\
\hline 0.1 & 2 & $\begin{array}{c}0,10,20,30, \\
40,50,60,70, \\
80,90\end{array}$ & 0.5 & 20 \\
\hline
\end{tabular}




\begin{tabular}{|c|c|c|c|c|}
\hline 0.1 & 2 & $0,45,90$ & $0.2,0.25,0.33$, & 30 \\
& & & $0.5,0.67$ & \\
\hline
\end{tabular}

145

146 Table 1. Microstructural parameters (porosity, pore diameter, pore angle, and pore aspect

147 ratio) for the numerical samples generated for this study. Two samples were generated for

148 each combination of parameters, resulting in a total of 98 numerical samples. 
porosity $=0.05$ pore diameter $=1 \mathrm{~mm}$

a)

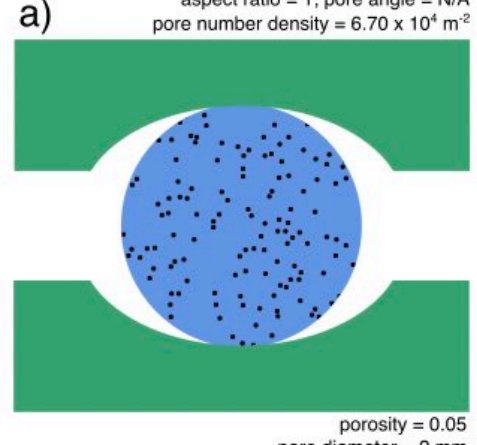

pore diameter $=2 \mathrm{~mm}$

d) aspect ratio $=1 ;$ pore angle $=\mathrm{N} / \mathrm{A}$
pore number density $=1.68 \times 10^{4} \mathrm{~m}^{-2}$

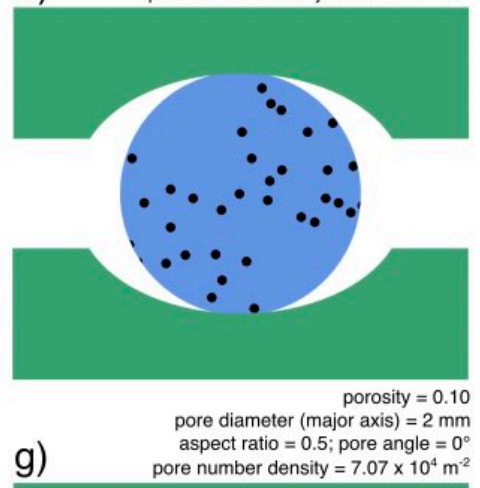

g)
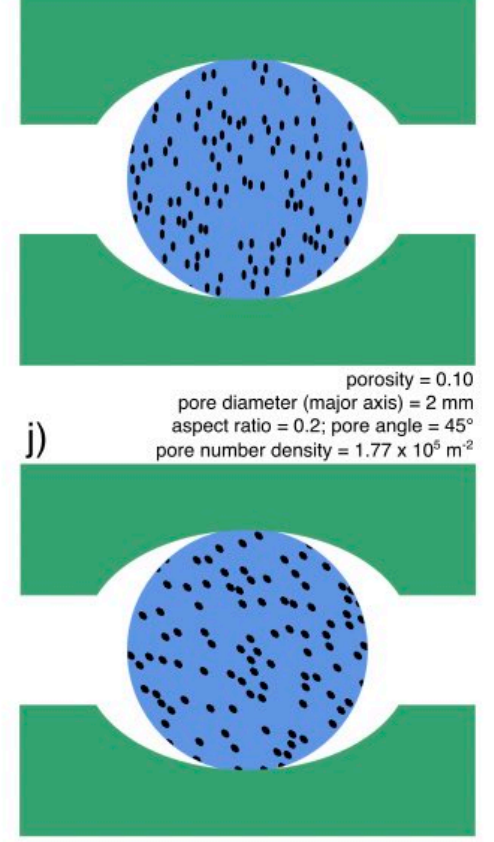

porosity $=0.15$

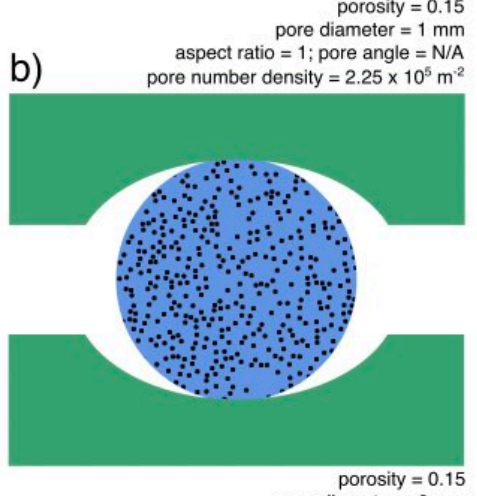

pore diameter $=2 \mathrm{~mm}$
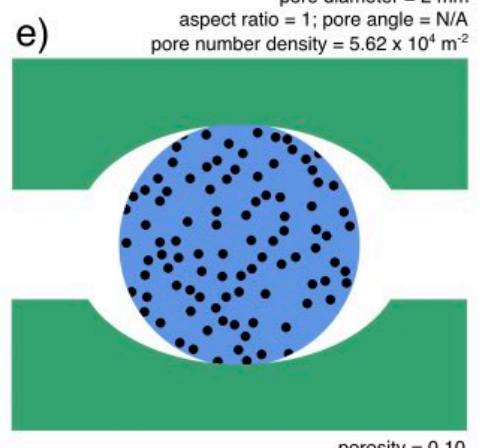

porosity $=0.10$ pore diameter $($ major axis) $=2 \mathrm{~mm}$ h) $\begin{array}{r}\text { aspect ratio }=0.5 \text {; pore angle }=45^{\circ} \\ \text { pore number density }=7.07 \times 10^{4} \mathrm{~m}^{-2}\end{array}$
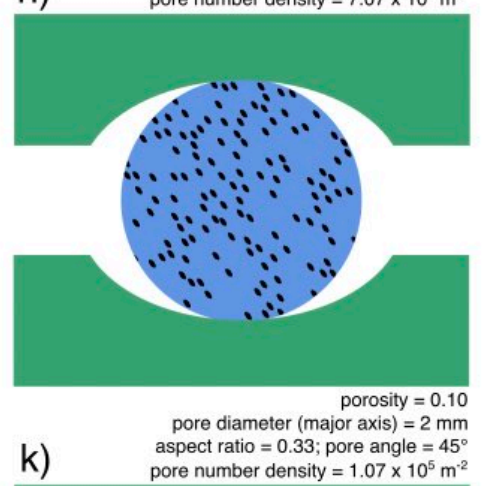

k) aspect ratio $=0.33$; pore angle $=45^{\circ}$

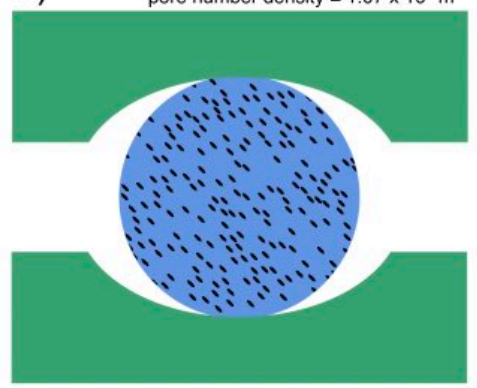

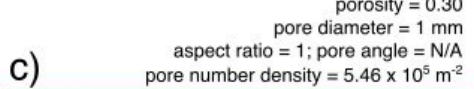

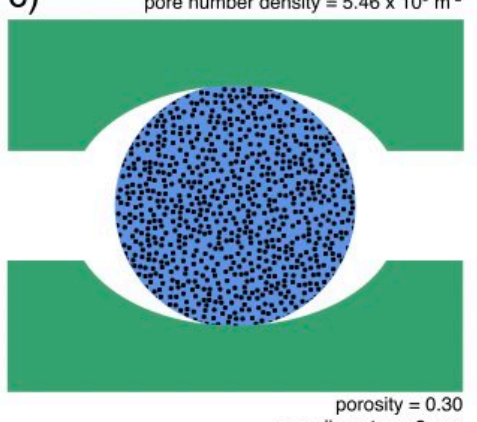

pore diameter $=2 \mathrm{~mm}$ f) $\begin{array}{r}\text { aspect ratio }=1 \text {; pore angle }=\mathrm{N} / \mathrm{A} \\ \text { pore number density }=1.36 \times 10^{5} \mathrm{~m}^{-2}\end{array}$
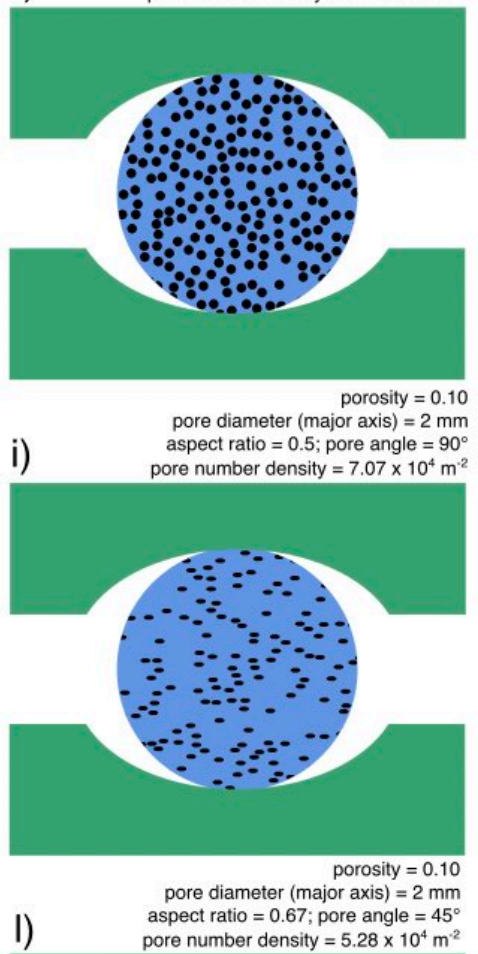

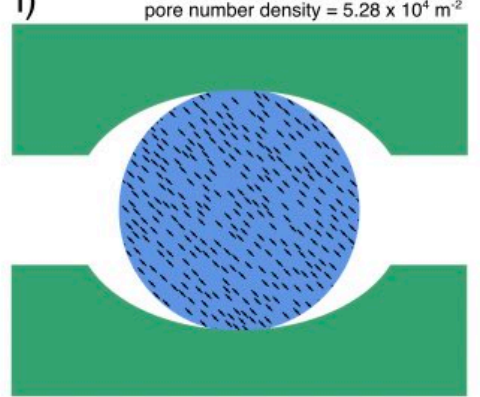

151 Figure 1. (a-1) Examples of the $50 \mathrm{~mm}$-diameter numerical samples generated for this study.

152 The green areas represent the loading platens typically used in laboratory experiments, the 
We then assigned physical and mechanical properties to the square pixels or elements

157 forming the circular samples. The elements comprising the pores were assigned a very small

158 value of Young's modulus, $E_{0}$, of $1.0 \times 10^{-8} \mathrm{MPa}$ in order to prevent the prevent the system of

159 equations from being ill-posed and to improve numerical stability. The elements comprising

160 the pores can deform freely, but not fail (see below). The elements representing the solid

161 groundmass of the sample were assigned values of Young's modulus, $E_{0}$, tensile strength, $\sigma_{t}$,

162 and compressive strength, $\sigma_{c}$, according to a Weibull probability density function (e.g., Rinne, 163 2008):

164

165

$$
x(u)=\frac{m}{u_{0}}\left(\frac{u}{u_{0}}\right)^{m-1} \exp \left[-\left(\frac{u}{u_{0}}\right)^{m}\right]
$$

166

167 Where $x(u)$ is the dependence of a given property on the distribution scale input, $u$, such that

$168 x(u)$ is replaced by each of $E_{0}(u), \sigma_{t}(u)$, or $\sigma_{c}(u)$ in determining the probability of a certain

169 groundmass element having a certain property. $m$ is the Weibull shape factor or "homogeneity

170 index" (high and low values of $m$ will create a homogenous and heterogenous sample

171 groundmass, respectively; see Tang et al., 2000; $\mathrm{Xu}$ et al., 2012), and $u$ and $u_{0}$ are the scale

172 parameter of an individual element and the average element value, respectively. We use values

173 of $E_{0}\left(u_{0}\right), \sigma_{t}\left(u_{0}\right), \sigma_{c}\left(u_{0}\right)$, and $m$ previously calibrated for volcanic rocks (Table 2; Heap et

174 al., 2014a, 2015a, 2016; Griffiths et al., 2017).

175

\begin{tabular}{|c|c|c|}
\hline Property & Units & Value \\
\hline Homogeneity index, $m$ & - & 3 \\
\hline $\begin{array}{c}\text { Mean uniaxial compressive } \\
\text { strength, } \sigma_{c}\left(u_{0}\right)\end{array}$ & $\mathrm{MPa}$ & 2300 \\
\hline
\end{tabular}




\begin{tabular}{|c|c|c|}
\hline $\begin{array}{c}\text { Mean Young's modulus, } \\
E_{0}\left(u_{0}\right)\end{array}$ & GPa & 100 \\
\hline Poisson's ratio & - & 0.25 \\
\hline $\begin{array}{c}\text { Ratio of compressive to } \\
\text { tensile strength }\end{array}$ & - & 10 \\
\hline Frictional angle $\left(^{\circ}\right)$ & $\circ$ & 30 \\
\hline
\end{tabular}

176

Table 2. The average physical and mechanical properties of the elements in the generated numerical samples. The same values were used in Heap et al. (2014a, 2015a, 2016) and

Griffiths et al. (2017).

Finally, the circular samples were deformed diametrically in compression using the 2D Rock Failure Process Analysis code (RFPA2D; Tang, 1997; Tang and Tang, 2011, 2020). RFPA $_{2 \mathrm{D}}$ is a numerical code based on elastic damage mechanics that has recently been used to explore the mechanical behaviour of volcanic rocks (e.g., Heap et al., 2014a, 2015a, 2016; Griffiths et al., 2017). The RFPA 2 D code has also been used to perform static and dynamic numerical tensile experiments on pore-free numerical samples (Zhu and Tang, 2006; Zhu et al., 2012). The circular numerical samples were deformed in increments of $0.002 \mathrm{~mm}$. Following the first $0.002 \mathrm{~mm}$ increment, the stress acting on each element within the numerical sample, $\sigma$, was calculated using the following linear elastic damage constitutive law:

$$
\sigma=E_{0}(1-D) \varepsilon
$$

Where $\varepsilon$ is the axial strain, $E_{0}$ is the Young's modulus of the element, and $D$ is the isotropic damage variable. If the stress acting on any one element exceeded either of the two strength criteria, the Mohr-Coulomb criterion and the maximum tensile criterion, then the element was damaged. The Mohr-Coulomb and maximum tensile strength criteria are defined, respectively, as follows: 


$$
D=\left\{\begin{aligned}
0, & 0 \leq \varepsilon<\varepsilon_{c 0} \\
1-\frac{\sigma_{c}}{\varepsilon E_{0}}, & \varepsilon_{c 0} \leq \varepsilon
\end{aligned}\right.
$$

$$
D=\left\{\begin{aligned}
0, & \varepsilon_{t 0}<\varepsilon \leq 0 \\
1-\frac{\sigma_{t}}{\varepsilon E_{0}}, & \varepsilon_{t}<\varepsilon \leq \varepsilon_{t 0} \\
1, & \varepsilon \leq \varepsilon_{t}
\end{aligned}\right.
$$

Where $\varepsilon_{t 0}$ and $\varepsilon_{c 0}$ are the critical strain in tension and compression, respectively. If an element was damaged, its Young's modulus is reduced according to the following elastic damage constitutive law:

$$
E=E_{0}(1-D)
$$

If $D=1$ for a particular element, the Young's modulus was assigned a value of $0.01 \mathrm{MPa}$ to prevent the system of equations from being ill-posed. If no elements were damaged in a particular loading increment, the sample was subjected to the next $0.002 \mathrm{~mm}$ increment. If elements were damaged, their Young's modulus was reduced according to Equation (5), and

213 the stress on each element was recalculated using Equation (2). If, following the recalculation 214 of stress, the stress on any of the elements within the sample exceeded one of the strength criteria, their Young's modulus was reduced, and the stress acting on all the elements (including damaged elements) was again recalculated. The process was repeated until no new elements

217 were damaged on a particular deformation increment. The sample was then subjected to the 218 next $0.002 \mathrm{~mm}$ increment. This procedure was repeated until the sample failed macroscopically 219 (marked by a stress drop and the formation of a throughgoing fracture). During the numerical experiments, the elements within the sample can move freely in the horizontal direction, but 
are fixed in the vertical direction due to the position on the loading platens (as is the case for tensile experiments in the laboratory, see below).

\subsection{Laboratory samples and experiments}

Cylindrical samples, $40 \mathrm{~mm}$ in diameter and $20 \mathrm{~mm}$ in length, were prepared from blocks of material have been the subject of recent laboratory studies: rhyodacite from Chaos Crags (Lassen Volcanic Center, USA; Ryan et al., 2020; Heap et al., 2021), trachyandesite from the Chaîne des Puys near Volvic (France; Heap and Violay, 2021), andesites from Volcán de Colima (Trans-Mexican Volcanic Belt, Mexico; Heap et al., 2015b; Farquharson et al., 2016, 2017) and Kumamoto (Japan; Farquharson et al., 2016), basaltic-andesites from Merapi volcano (Sunda arc, Indonesia; Heap et al., 2019b), basalt from Mt Etna (Italy; Zhu et al., 2016), and tuff from Campi Flegrei and Mt Epomeo (both Italy; Heap et al., 2014b, Marmoni et al., 2017; Heap et al., 2018). Samples were prepared to a diameter of $40 \mathrm{~mm}$, rather than $50 \mathrm{~mm}$ (the diameter used for the numerical experiments), due to the small size of some of the blocks of material. We do not anticipate that this reduction in diameter influenced our results.

Backscattered scanning electron microscope (SEM) images for all of the studied materials are provided in Figure 2 (optical microscope images are provided for the two tuffs from Campi Flegrei). We also determined the mean 2D equivalent pore diameter (the average of the maximum and minimum Feret diameter) and pore aspect ratio (the ratio of the minor to major semi axis) of the most-common macropore size from these microstructural images using open-source software ImageJ (in all samples except the three tuffs, rocks for which it is difficult to determine the most-common macropore size due to their heterogeneity). These data are available in Table 3. Although pore size and shape vary in the studied materials (Figure 2), a single value of pore diameter and pore aspect ratio for each rock is required so we can compare our experimental data with the results of the numerical modelling. 
247 Center in California, USA) was sampled from the Chaos Jumbles deposit (about $2 \mathrm{~km}$ from the

248 volcano summit), a cold-rock avalanche deposit resulting from the collapse of Dome C about 249350 years ago (Clynne and Muffler, 2017; Ryan et al., 2020). The rhyodacite has a porphyritic 250 texture containing phenocrysts of predominantly plagioclase and potassium feldspar within a 251 microcrystalline groundmass (Figure 2a; Ryan et al., 2020). The mean macropore diameter and 252 aspect ratio is $59 \mu \mathrm{m}$ and 0.55 , respectively (Table 3 ); microcracks are also visible in the rhyodacite from Chaos Crags (Figure 2a). et al., 2019) was sampled from the La Lumbre debris-flow track on the southwestern flank of the volcano (about 6-7 $\mathrm{km}$ from the volcano summit) (Farquharson et al., 2017). The EZ andesite block, also from Volcán de Colima, was sampled from the El Zarco riverbed on the southeastern flank of the volcano (about $12 \mathrm{~km}$ from the volcano summit) (Farquharson et al., 2016). Both andesites from Volcán de Colima have a porphyritic texture consisting of predominantly plagioclase and pyroxene within a microcrystalline groundmass; both andesites also contain microcracks (Figures $2 \mathrm{~b}$ and $2 \mathrm{c}$ ). Although the average pore diameter is much larger in andesite LLB than EZ (204 and $22 \mu \mathrm{m}$, respectively), the mean pore aspect ratio is very similar (0.53 and 0.50 , respectively) (Table 3$)$. The andesite from Kumamoto (KA), from 264 a quarry in the Kumamoto prefecture in southwest Japan, has porphyritic texture containing 265 phenocrysts of predominantly plagioclase within a microcrystalline groundmass (Figure 2d).

266 Kumamoto andesite has a high plagioclase content of about 50\% (Nara et al., 2010a). The mean 267 pore diameter and pore aspect ratio of Kumamoto andesite is $52 \mu \mathrm{m}$ and 0.52 , respectively 268 (Table 3). No microcracks are observable in Kumamoto andesite (Figure 2d). The block of trachyandesite from the Chaîne des Puys (France) was sourced from a quarry Volvic (VT). The trachyandesite from Volvic has an aphanitic texture (Figure 2e) and contains pores with a mean 
diameter and aspect ratio of $161 \mu \mathrm{m}$ and 0.58 , respectively (Table 3 ). No microcracks are observable in Volvic trachyandesite (Figure 2e).

274 (Heap et al., 2019b). These rocks are variably altered by hydrothermal processes. Block M-U 275 is the least altered, blocks M-SA1 and MSA-2 are slightly altered, and block M-HA1 is highly altered. The most abundant alteration minerals in these basaltic-andesites are K-feldspar, $\mathrm{K}$ Na-alunite, and gypsum. Blocks M-U, M-SA1, MSA-2, and M-HA1 contain 19, 9, 13, and 6 wt.\% of K-feldspar, $0,0.5$, 4, and 5 wt. $\%$ of gypsum, and $0,1,8.5$, and 11 wt.\% of K-Naalunite, respectively (Heap et al., 2019b). All four blocks are characterised by a porphyritic magmatic texture containing original phenocrysts of predominantly plagioclase and pyroxene, and secondary K-feldspar phenocrysts, within a microcrystalline groundmass (Figures 2f, 2g, 2h, and 2i; Heap et al., 2019b). Blocks M-U, M-SA1, MSA-2, and M-HA1 contain average pore diameters of $322,180,99$, and $133 \mu \mathrm{m}$, respectively, and mean pore aspect ratios of 0.63 , $0.49,0.58$, and 0.52 , respectively (Table 3 ).

The basalt from Mt Etna (EB) was sourced from a quarry on the southern flank of the volcano (about $15 \mathrm{~km}$ from the volcano summit) (Zhu et al., 2016). The basalt from Mt Etna 287 has an aphanitic texture (Figure $2 \mathrm{j}$ ), with very rare plagioclase, pyroxene, and olivine 288 phenocrysts (Zhu et al., 2016). The basalt contains pores with a mean diameter and aspect ratio 289 of $16 \mu \mathrm{m}$ and 0.53 , respectively (Table 3), and long microcracks (which can be longer than 1 $290 \mathrm{~mm}$; Figure 2j). 

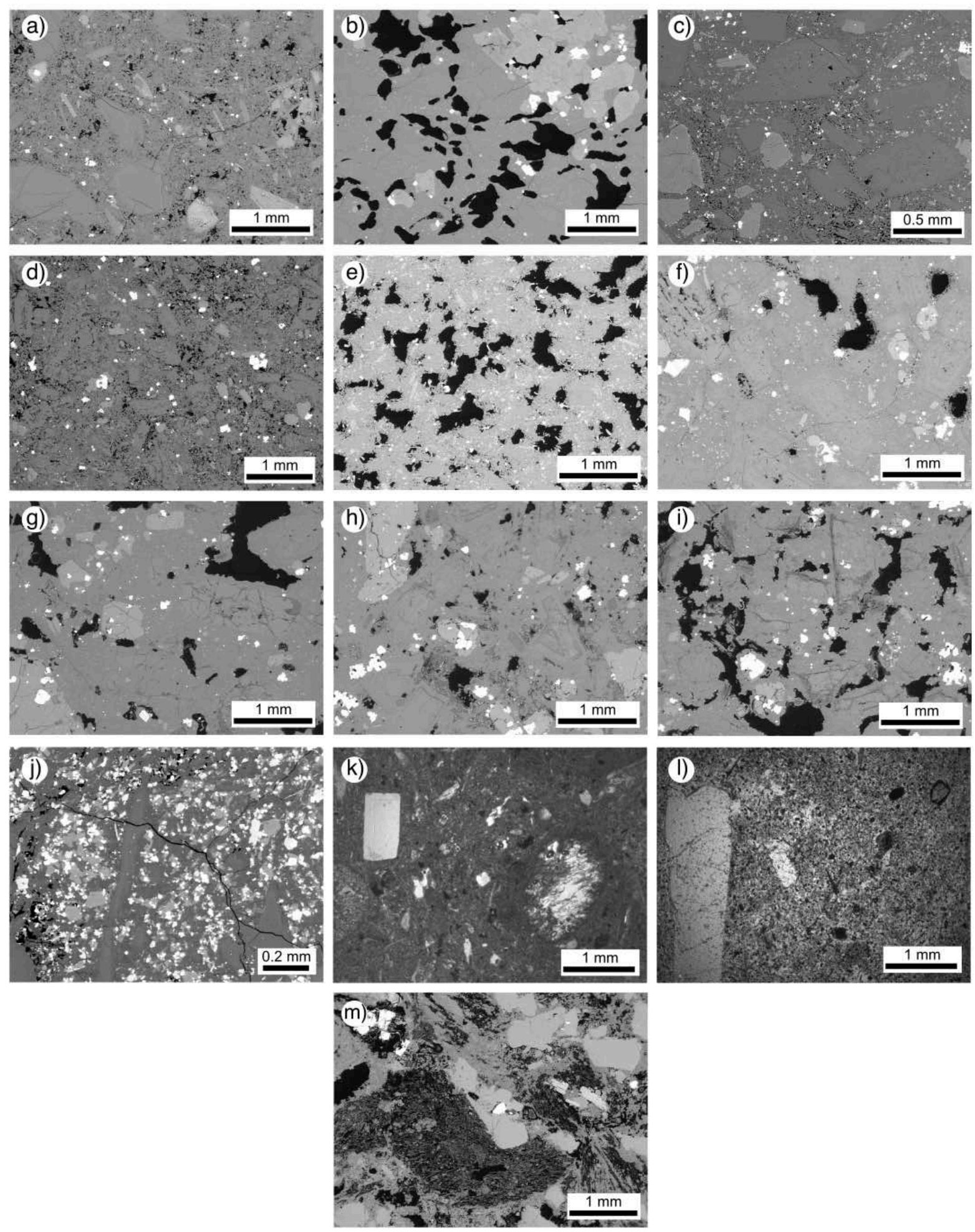

293 Figure 2. Backscattered scanning electron microscope (SEM) images of the rocks used in this

294 study (panels (k) and (l) are transmitted-light optical microscope images). (a) Dacite from

295 Chaos Crags (USA). (b) Andesite LLB from Volcán de Colima (Mexico). (c) Andesite EZ

296 from Volcán de Colima (Mexico). (d) Andesite from Kumamoto (Japan). (e) Trachyandesite 

Basaltic-andesite (M-SA1) from Merapi volcano. (h) Basaltic-andesite (M-SA2) from Merapi volcano. (i) Basaltic-andesite (M-HA1) from Merapi volcano. (j) Basalt from Mt Etna (Italy). (k) Neapolitan Yellow Tuff from Campi Flegrei (Italy). (1) Grey Campanian Ignimbrite from Campi Flegrei (Italy). (m) Mt Epomeo Green Tuff from Ischia Island (Italy). In all cases, the non-black greyscale represents the crystals and groundmass and the black areas in the images represent void space (pores and microcracks). an open quarry at Monte San Severino within the inferred Campi Flegrei caldera, and the Grey Campanian Ignimbrite (WGI), sourced from an open quarry northwest of Caserta (Heap et al., 2014b). The Mt Epomeo Green Tuff (MEGT) was collected from the flank of Mt Epomeo on Ischia Island (Italy) (Marmoni et al., 2017; Heap et al., 2018). All three tuffs are texturally heterogeneous pyroclastic flow deposits that contain fragments of lithics, phenocrysts, and porous lapilli within a fine-grained matrix (Figures 2k, 21, and 2m). NYT and MEGT contain abundant clays and zeolites (Heap et al., 2014b, 2018), not present in WGI (Heap et al., 2014b).

313 The pore diameter and pore aspect ratio of the three tuffs are very microstructurally heterogeneous and, for this reason, we consider it impossible to assign a mean pore diameter and aspect ratio for these rocks.

The cylindrical samples prepared from these blocks were washed with water and dried

317 in a vacuum oven at $40{ }^{\circ} \mathrm{C}$ for at least $48 \mathrm{~h}$. The connected porosity of each sample was 318 calculated using the bulk sample volume and the skeletal (solid) sample volume measured by a 319 helium pycnometer. The samples were then deformed diametrically by applying a vertical 320 compressive force to the loading platens at a constant stressing rate until tensile failure, 321 experiments commonly referred to as "Brazilian" tests (Bieniawski and Hawkes, 1978; Perras 
and Diederichs, 2014). A schematic diagram of the experimental setup is provided as Figure 3.

323 Axial displacement and axial load were measured using a linear variable differential transducer

324 (LVDT) and a load cell, respectively. The displacement accumulated within the load chain was

325 subtracted from the axial displacement. Tensile stress, $\sigma_{t}$, was calculated using:

$$
\sigma_{t}=\frac{2 P}{\pi d L} \quad(6)
$$

where $d$ and $L$ are the diameter and thickness of the sample, respectively, and $P$ is the force applied to the sample diametrically in compression. The tensile strength of the rock was taken as the tensile stress required to form the first macrofracture within the sample. All of our laboratory experiments were performed at ambient laboratory pressure and temperature.

\begin{tabular}{|c|c|c|}
\hline Rock type & Pore diameter $(\boldsymbol{\mu m})$ & Pore aspect ratio \\
\hline Chaos Crags dacite (CCC) & 59 & 0.55 \\
\hline Colima andesite (LLB) & 204 & 0.53 \\
\hline Colima andesite (EZ) & 22 & 0.50 \\
\hline Kumamoto andesite (KA) & 52 & 0.52 \\
\hline Volvic trachyandesite (VT) & 161 & 0.58 \\
\hline Merapi basaltic-andesite (M-U) & 322 & 0.63 \\
\hline Merapi basaltic-andesite (M-SA1) & 180 & 0.49 \\
\hline Merapi basaltic-andesite (M-SA2) & 99 & 0.58 \\
\hline Merapi basaltic-andesite (M-HA1) & 133 & 0.52 \\
\hline Mt Etna basalt (EB) & 16 & 0.53 \\
\hline
\end{tabular}

Table 3. The mean macropore equivalent diameter (the average of the maximum and minimum Feret diameter) and the average macropore aspect ratio (the ratio of the minor to major semi axis) for the studied rock types (excluding the three tuffs), determined on backscattered scanning electron microscope images (Figure 2) using ImageJ. 


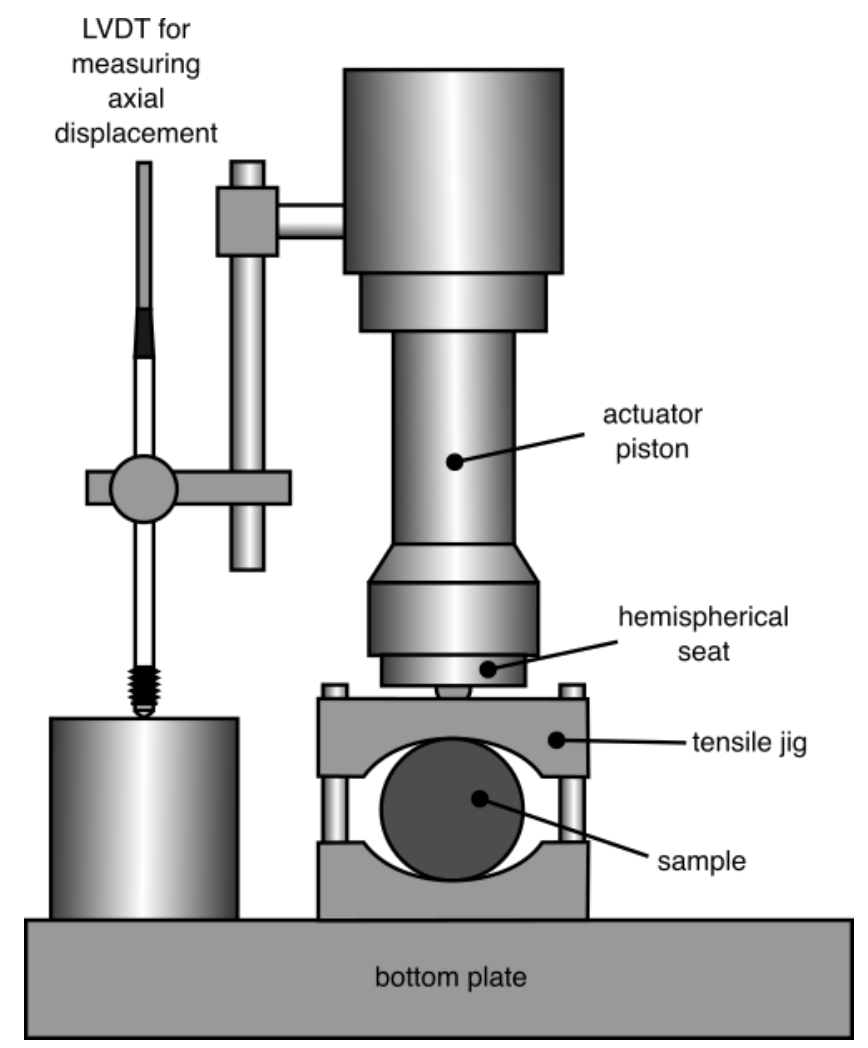

Figure 3. Schematic diagram of the laboratory setup for the indirect tensile strength

experiments performed for this study. LVDT - linear variable differential transducer. Sample radius is $20 \mathrm{~mm}$.

\section{Results}

\section{$346 \quad 3.1$ Numerical experiments}

347 The data from the numerical experiments are provided in Table 4. A representative 348 force-displacement curve and snapshots of the numerical sample showing the development of 349 the macroscopic fracture are shown in Figure 4. Macroscopic failure was signalled by a force 350 drop, the result of the formation of a macroscopic tensile fracture (Figure 4). 


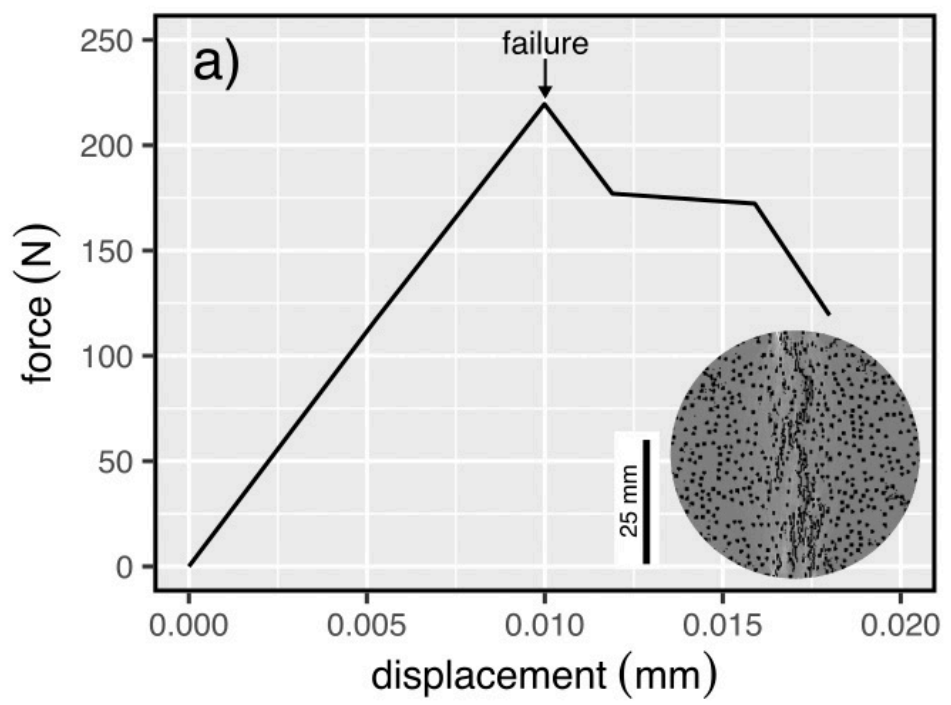

b)
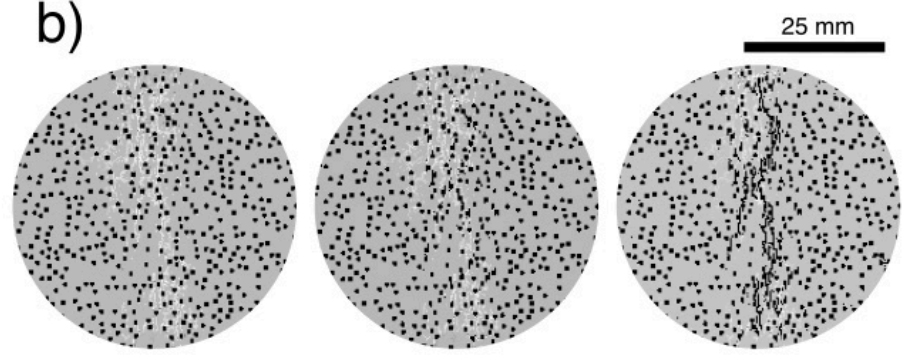

353 Figure 4. (a) Force-displacement curve for a numerical sample containing circular pores with a diameter of $1 \mathrm{~mm}$ and a porosity of 0.3 . Inset shows an image of the sample following failure, showing the throughgoing tensile fracture.

(b) Three snapshots of the numerical sample showing the development of the macroscopic fracture (from left to right).

Figure 5 shows the results of numerical experiments designed to understand the 359 influence of pore angle on the tensile strength of volcanic rock. In these numerical experiments, 360 the porosity, pore aspect ratio, and pore diameter (the pore major axis) were fixed at $0.1,0.5$, 361 and $2 \mathrm{~mm}$, respectively, and the pore angle was varied from 0 to $90^{\circ}$. These data show that tensile strength decreases from $\sim 2.75 \mathrm{MPa}$ at an angle of $0^{\circ}$ to $\sim 2.5 \mathrm{MPa}$ at an angle of $90^{\circ}$

\section{3 (Figure 5).}




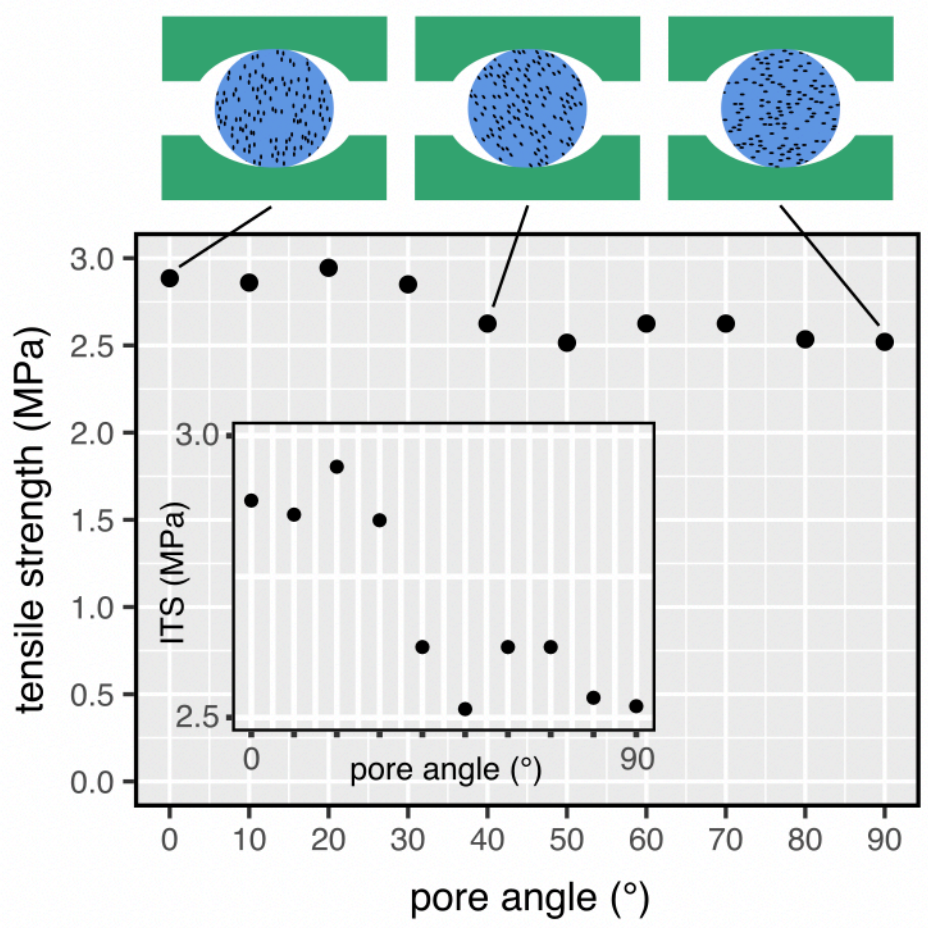

Figure 5. Indirect tensile strength as a function of pore angle from the numerical experiments.

The porosity, pore aspect ratio, and pore diameter (the pore major axis) were fixed at, respectively, $0.1,0.5$, and $2 \mathrm{~mm}$ for these from the numerical experiments (see Table 1). Inset shows a zoom of the data. Examples of the undeformed numerical samples are provided above the graph (green - sample holder; blue - solid sample; black - porosity).

Figure 6 shows the influence of porosity and pore diameter on the tensile strength of volcanic rock. In these numerical experiments, the pore aspect ratio was 1 (the pores were circular) and the porosity was varied from 0.02 to 0.35 and the pore diameter was varied from 1 to $2 \mathrm{~mm}$ (Table 1). If we consider the samples with a pore diameter of $1 \mathrm{~mm}$, the tensile strength was reduced from $\sim 4.5 \mathrm{MPa}$ at a porosity of 0.02 to $\sim 2.5 \mathrm{MPa}$ at a porosity of 0.35 (Figure 6). Reductions in strength as a function of porosity are of a similar magnitude when the pore diameter is 1.5 and $2 \mathrm{~mm}$. Figure 6 also shows that, for a given porosity, tensile strength decreases as a function of increasing pore diameter. For example, for a porosity of 0.2 , tensile 
results show that tensile strength decreases as pore diameter increases over the entire porosity range tested (0.02 to 0.35 ; Figure 6$)$.

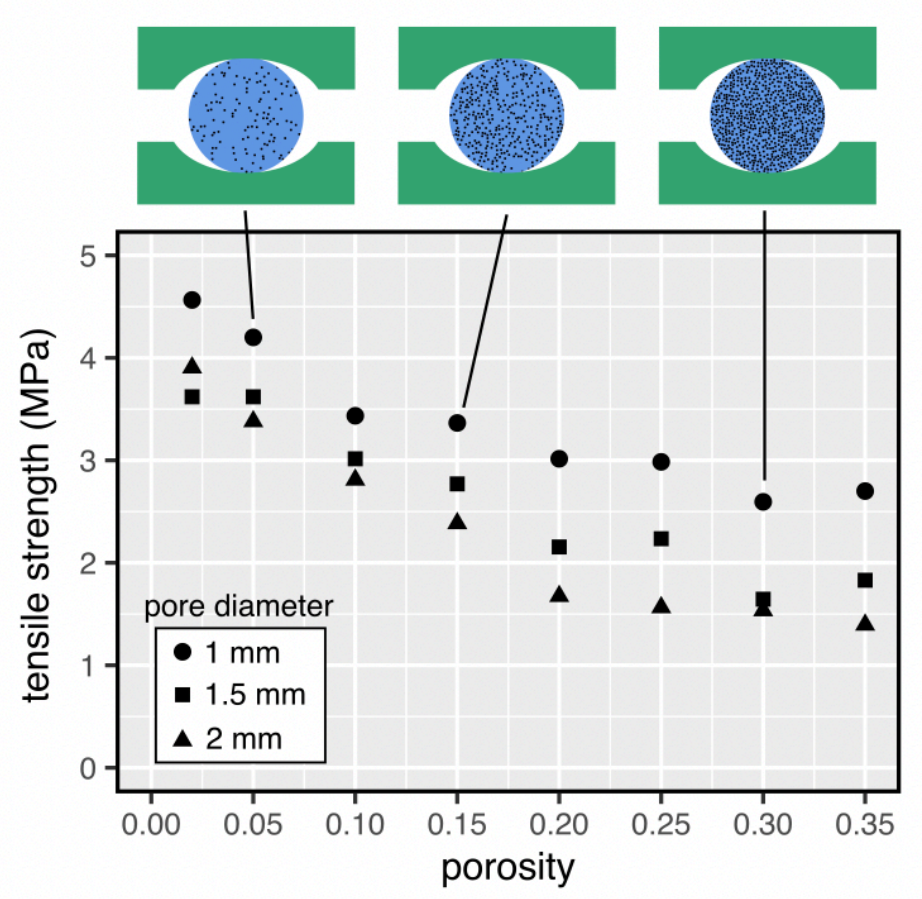

Figure 6. Indirect tensile strength as a function of porosity from the numerical experiments for three different pore diameters: $1 \mathrm{~mm}$ (circles), $1.5 \mathrm{~mm}$ (squares), and $2 \mathrm{~mm}$ (triangles).

The pore aspect ratio was fixed at 1 (i.e. circular pores) for these from the numerical experiments (Table 1). Examples of the undeformed numerical samples are provided above the graph (green - sample holder; blue - solid sample; black - porosity).

Figure 7 shows the influence of pore aspect ratio on the tensile strength of volcanic rock.

392 In these numerical experiments, the porosity and the maximum pore diameter (the pore major axis) were fixed at 0.1 and $2 \mathrm{~mm}$, respectively, and the pore aspect ratio was varied from 0.2 to 0.67 and the pore angle was varied from 0 to $90^{\circ}$. Figure 7 shows that the influence of pore aspect ratio depends on the pore angle. When the pore angle is $0^{\circ}$, a decrease in pore aspect ratio increases the tensile strength from $\sim 2.75 \mathrm{MPa}$ at a pore aspect ratio of 1 to $\sim 4.5 \mathrm{MPa}$ at a 
pore aspect ratio of 0.2 . When the pore angle is $90^{\circ}$, a decrease in pore aspect ratio does not 398 significantly change the tensile strength: strength is reduced from $\sim 2.75 \mathrm{MPa}$ at a pore aspect ratio of 1 to $\sim 2.5 \mathrm{MPa}$ at a pore aspect ratio of 0.2 .

400

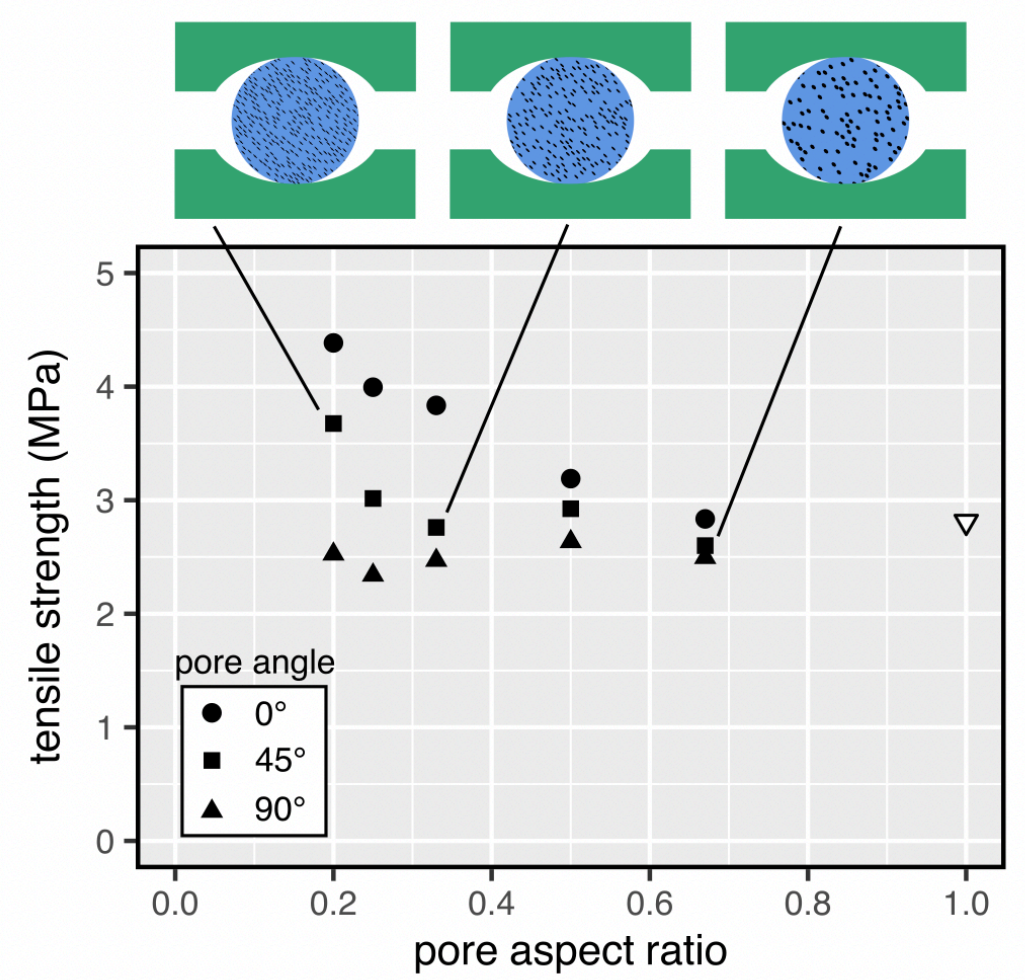

401

Figure 7. Indirect tensile strength as a function of pore aspect ratio from the numerical experiments for three different pore angles to the applied load: $0^{\circ}$ (filled circles), $45^{\circ}$ (filled squares), and $90^{\circ}$ (filled triangles). The porosity and maximum pore diameter (the pore major axis) were fixed at, respectively, 0.1 and $2 \mathrm{~mm}$ for these numerical experiments (Table 1). Examples of the undeformed numerical samples are provided above the graph (green sample holder; blue - solid sample; black - porosity).

\begin{tabular}{|c|c|c|c|c|}
\hline Porosity & $\begin{array}{c}\text { Pore diameter } \\
\text { (circle), } 2 r, \text { or } \\
\text { major axis } \\
\text { diameter, } 2 r_{b} \\
\text { (ellipse) }\end{array}$ & Pore angle $\left(^{\circ}\right)$ & $\begin{array}{c}\text { Pore aspect } \\
\text { ratio }\end{array}$ & $\begin{array}{c}\text { Indirect tensile } \\
\text { strength (MPa) }\end{array}$ \\
\hline
\end{tabular}




\begin{tabular}{|c|c|c|c|c|}
\hline & $(\mathrm{mm})$ & & & \\
\hline 0.1 & 2 & 0 & 0.5 & 2.89 \\
\hline 0.1 & 2 & 10 & 0.5 & 2.86 \\
\hline 0.1 & 2 & 20 & 0.5 & 2.95 \\
\hline 0.1 & 2 & 30 & 0.5 & 2.85 \\
\hline 0.1 & 2 & 40 & 0.5 & 2.63 \\
\hline 0.1 & 2 & 50 & 0.5 & 2.52 \\
\hline 0.1 & 2 & 60 & 0.5 & 2.63 \\
\hline 0.1 & 2 & 70 & 0.5 & 2.63 \\
\hline 0.1 & 2 & 80 & 0.5 & 2.54 \\
\hline 0.1 & 2 & 90 & 0.5 & 2.52 \\
\hline 0.02 & 1 & - & 1 & 4.57 \\
\hline 0.05 & 1 & - & 1 & 4.20 \\
\hline 0.1 & 1 & - & 1 & 3.44 \\
\hline 0.15 & 1 & - & 1 & 3.37 \\
\hline 0.2 & 1 & - & 1 & 3.02 \\
\hline 0.25 & 1 & - & 1 & 2.99 \\
\hline 0.3 & 1 & - & 1 & 2.60 \\
\hline 0.35 & 1 & - & 1 & 2.70 \\
\hline 0.02 & 1.5 & - & 1 & 3.62 \\
\hline 0.05 & 1.5 & - & 1 & 3.62 \\
\hline 0.1 & 1.5 & - & 1 & 3.02 \\
\hline 0.15 & 1.5 & - & 1 & 2.77 \\
\hline 0.2 & 1.5 & - & 1 & 2.16 \\
\hline 0.25 & 1.5 & - & 1 & 2.24 \\
\hline 0.3 & 1.5 & - & 1 & 1.65 \\
\hline 0.35 & 1.5 & - & 1 & 1.83 \\
\hline 0.02 & 2 & - & 1 & 3.91 \\
\hline 0.05 & 2 & - & 1 & 3.38 \\
\hline 0.1 & 2 & - & 1 & 2.81 \\
\hline 0.15 & 2 & - & 1 & 2.39 \\
\hline 0.2 & 2 & - & 1 & 1.68 \\
\hline 0.25 & 2 & - & 1 & 1.57 \\
\hline 0.3 & 2 & - & 1 & 1.54 \\
\hline 0.35 & 2 & - & 1 & 1.40 \\
\hline 0.1 & 2 & 0 & 0.67 & 2.84 \\
\hline 0.1 & 2 & 0 & 0.5 & 3.19 \\
\hline 0.1 & 2 & 0 & 0.33 & 3.84 \\
\hline 0.1 & 2 & 0 & 0.25 & 4.00 \\
\hline 0.1 & 2 & 0 & 0.2 & 4.39 \\
\hline 0.1 & 2 & 45 & 0.67 & 2.60 \\
\hline 0.1 & 2 & 45 & 0.5 & 2.93 \\
\hline
\end{tabular}




\begin{tabular}{|l|l|c|c|c|}
\hline 0.1 & 2 & 45 & 0.33 & 2.76 \\
\hline 0.1 & 2 & 45 & 0.25 & 3.02 \\
\hline 0.1 & 2 & 45 & 0.2 & 3.68 \\
\hline 0.1 & 2 & 90 & 0.67 & 2.50 \\
\hline 0.1 & 2 & 90 & 0.5 & 2.64 \\
\hline 0.1 & 2 & 90 & 0.33 & 2.47 \\
\hline 0.1 & 2 & 90 & 0.25 & 2.34 \\
\hline 0.1 & 2 & 90 & 0.2 & 2.53 \\
\hline
\end{tabular}

Table 4. Results of the numerical experiments. Pore angle is the angle between the loading direction and the major axis of the elliptical pore. Pore aspect ratio is the ratio of the minor to major semi axis of the pore (a circular pore has a pore aspect ratio of one). Indirect tensile strength is an average of two numerical experiments.

3.2 Laboratory experiments

All of the laboratory data are provided in Table 5. Representative laboratory forcedisplacement curves are shown in Figure 8. Macroscopic failure was signalled by a stress drop, the result of the formation of a throughgoing tensile fracture (Figure 8). Figure 9 shows the laboratory indirect tensile strengths as a function of connected porosity (Figure 9a), pore diameter (Figure 9b), and pore aspect ratio (Figure 9c). The data show that indirect tensile strength is reduced as porosity is reduced, from $\sim 11-12 \mathrm{MPa}$ at a porosity of $\sim 0.05$ to $\sim 1-2$

Etna, have the highest tensile strength $(\sim 11-12 \mathrm{MPa})$, and the highest porosity samples, the

424 three tuffs (from Campi Flegrei and Mt Epomeo), have the lowest tensile strength ( 1-2 MPa)

425 (Figure 9a). Tensile strength does not vary systematically as a function of increasing pore diameter (Figure $9 \mathrm{~b}$ ) and, because of the narrow range of pore aspect ratio $(\sim 0.5-0.6$; Table 3 ),

427 it is difficult to assess the influence of pore aspect ratio on the tensile strength of the studied 428 volcanic rocks (Figure 9c). 


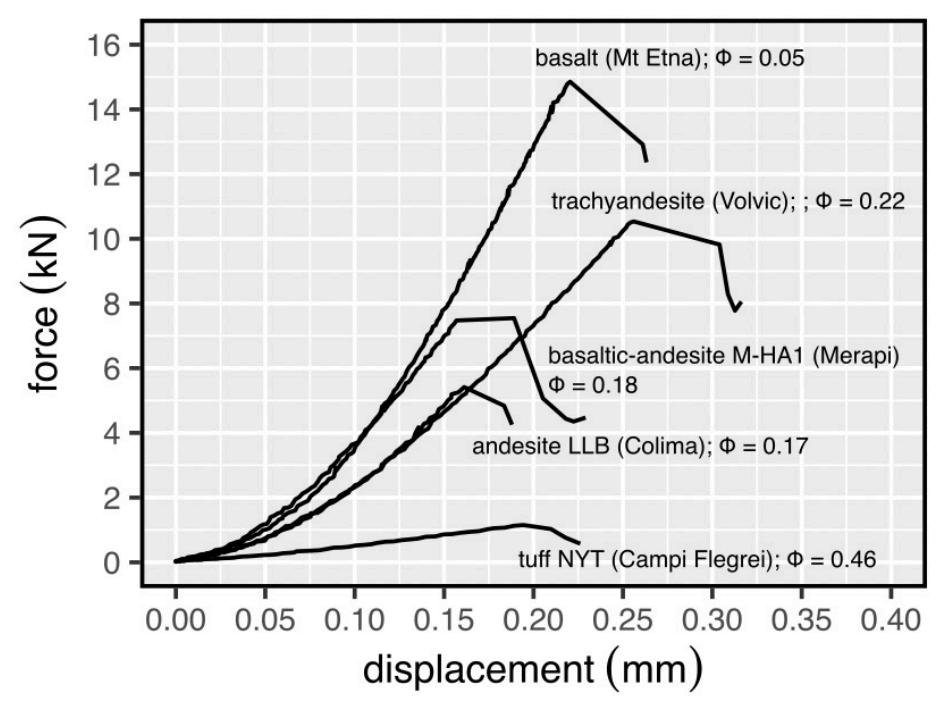

431 Figure 8. Representative laboratory force-displacement curves from the laboratory indirect tensile strength experiments (all data provided in Table 5).

\begin{tabular}{|c|c|c|c|}
\hline Location & Rock type & Connected porosity & $\begin{array}{c}\text { Indirect tensile } \\
\text { strength (MPa) }\end{array}$ \\
\hline Chaos Crags (USA) & rhyodacite (CCC) & 0.14 & 5.8 \\
\hline Chaos Crags (USA) & rhyodacite (CCC) & 0.14 & 5.1 \\
\hline Mt Etna (Italy) & basalt (EB) & 0.05 & 11.7 \\
\hline Mt Etna (Italy) & basalt (EB) & 0.05 & 11.1 \\
\hline Volvic (France) & trachyandesite (VT) & 0.22 & 8.4 \\
\hline Volvic (France) & trachyandesite (VT) & 0.22 & 4.9 \\
\hline $\begin{array}{c}\text { Volcán de Colima } \\
\text { (Mexico) }\end{array}$ & andesite (LLB) & 0.16 & 4.3 \\
\hline $\begin{array}{c}\text { Volcán de Colima } \\
\text { (Mexico) }\end{array}$ & andesite (LLB) & 0.17 & 6.5 \\
\hline $\begin{array}{c}\text { Volcán de Colima } \\
\text { (Mexico) }\end{array}$ & andesite (EZ) & 0.09 & 5.9 \\
\hline $\begin{array}{c}\text { Volcán de Colima } \\
\text { (Mexico) }\end{array}$ & andesite (EZ) & 0.08 & 10.1 \\
\hline Kumamoto (Japan) & andesite (KA) & 0.13 & 10.1 \\
\hline Kumamoto (Japan) & andesite (KA) & 0.14 & 7.4 \\
\hline $\begin{array}{c}\text { Merapi (Indonesia) } \\
\text { basaltic-andesite (M- } \\
\text { U) }\end{array}$ & 0.08 & 7.0 \\
\hline $\begin{array}{c}\text { Merapi (Indonesia) } \\
\text { basaltic-andesite (M- }\end{array}$ & 0.09 & \\
\hline
\end{tabular}




\begin{tabular}{|c|c|c|c|}
\hline Merapi (Indonesia) & $\begin{array}{c}\text { basaltic-andesite (M- } \\
\text { SA2) }\end{array}$ & 0.09 & 9.7 \\
\hline Merapi (Indonesia) & $\begin{array}{c}\text { basaltic-andesite (M- } \\
\text { SA2) }\end{array}$ & 0.09 & 10.1 \\
\hline Merapi (Indonesia) & $\begin{array}{c}\text { basaltic-andesite (M- } \\
\text { SA1) }\end{array}$ & 0.22 & 3.0 \\
\hline Merapi (Indonesia) & $\begin{array}{c}\text { basaltic-andesite (M- } \\
\text { SA1) }\end{array}$ & 0.25 & 2.1 \\
\hline Merapi (Indonesia) & $\begin{array}{c}\text { basaltic-andesite (M- } \\
\text { HA1) }\end{array}$ & 0.18 & 6.0 \\
\hline Merapi (Indonesia) & $\begin{array}{c}\text { basaltic-andesite (M- } \\
\text { HA1) }\end{array}$ & 0.21 & 4.6 \\
\hline Campi Flegrei (Italy) & tuff (NYT) & 0.46 & 1.2 \\
\hline Campi Flegrei (Italy) & tuff (NYT) & 0.46 & 0.9 \\
\hline Campi Flegrei (Italy) & tuff(WGI) & 0.50 & 2.4 \\
\hline Campi Flegrei (Italy) & tuff (WGI) & 0.50 & 2.1 \\
\hline Mt Epomeo (Italy) & tuff (MEGT) & 0.44 & 0.9 \\
\hline Mt Epomeo (Italy) & tuff (MEGT) & 0.46 & 0.8 \\
\hline
\end{tabular}

435 Table 5. Results of the laboratory indirect tensile experiments performed on a selection of 436 volcanic rocks (rhyodacite, basalt, andesite, basaltic-andesite, trachyandesite, and tuff) (see Figure 2 for microstructural images of all the studied rocks). 

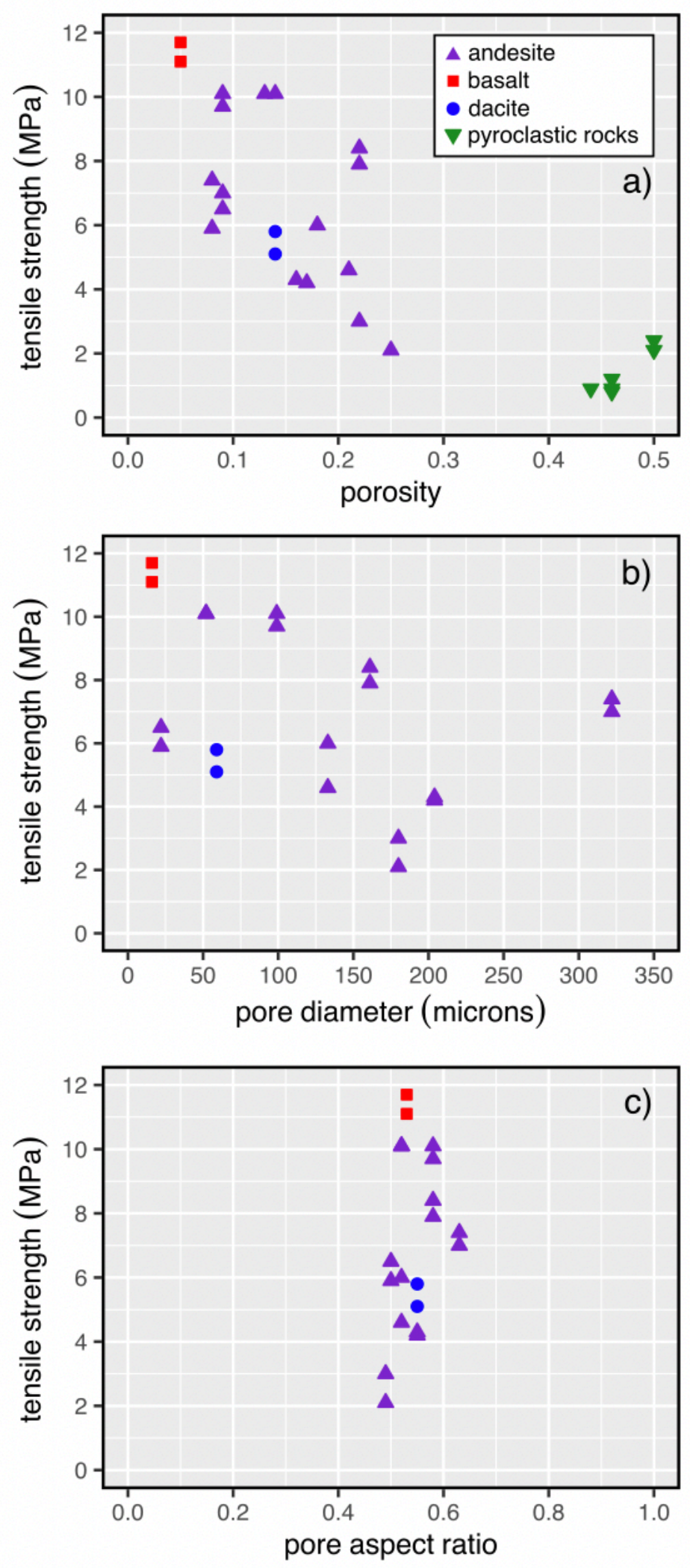

440 Figure 9. Laboratory indirect tensile strength for the volcanic rocks deformed for this study 441 as a function of (a) connected porosity, (b) average macropore diameter, and (c) average macropore aspect ratio (data provided in Tables 3 and 5). 


\section{Discussion}

The results of our numerical experiments highlight that porosity and pore geometry

446 (pore diameter, pore aspect ratio, and pore angle) can greatly influence the tensile strength of

447 rocks (Figures 5, 6, and 7). Our results are, therefore, in qualitative agreement with those for 448 the compressive strength of rocks provided in Heap et al. (2014a) and Griffiths et al. (2017). 449 For example, Heap et al. (2014a) showed that the compressive strength of volcanic rocks 450 decreases as porosity and pore diameter increase, in accordance with the numerical tensile experiments performed for this study (Figure 6). Griffiths et al. (2017) showed, using an analytical solution for the tangential (hoop) stress along the boundary of a two-dimensional elliptical void, that the applied stress required to generate a given maximum hoop stress is higher when the pore angle is higher. These calculations explain why tensile strength decreases as a function of pore angle in our numerical experiments (Figure 5). Griffiths et al. (2017) used the same analytical solution to show that the applied stress required to maintain a given hoop stress decreases as aspect ratio decreases for high pore angles, but increases as aspect ratio decreases for low pore angles, similar to numerical data for tensile strength presented here (Figure 7). In our numerical experiments, tensile strength is not substantially influenced by aspect ratio when the pore angle is $90^{\circ}$ (Figure 7). We highlight that the aspect ratio is varied in our numerical samples by changing the minor axis length only and so, when the pore angle is $90^{\circ}$, the total length of void pixels in the horizontal direction remains the same and could explain the near-constant tensile strength for the range of aspect ratios studied here $(0.2-0.67)$. We explored here the tensile strength of volcanic rocks containing pores. In nature, however, volcanic rocks can contain both pores and crystals (e.g., Voltolini et al., 2011). The numerical experiments presented in Heap et al. (2016) show that the presence of crystals can

467 reduce the compressive strength of volcanic rock. It is likely, therefore, that crystals may also 
serve to reduce the tensile strength of volcanic rock, offering an exciting avenue for future research.

\subsection{Comparing the numerical and laboratory experiments}

Figure 10a shows tensile strength decreases as a function of porosity for both the numerical (filled symbols; pore diameter from 1 to $2 \mathrm{~mm}$ ) and laboratory experiments (open symbols; pore diameter $<1 \mathrm{~mm}$; Table 3 ). The tensile strengths from the laboratory experiments are typically larger than those from the numerical experiments, and is likely the result of the smaller pore diameter of the laboratory samples (16-322 $\mu \mathrm{m}$; Figure 2; Table 3) compared to the numerical samples (1-2 mm; Figure 1), a factor known to influence tensile strength (Figure 6). We also note that the pores within the numerical samples in Figure 10a are circular, which is not the case for the laboratory samples (pore aspect ratio $\sim 0.5-0.6$; Table 3 ). Figure $10 \mathrm{~b}$ shows tensile strength as a function of pore aspect ratio from the numerical (filled symbols; pore angle from 0 to $90^{\circ}$ ) and laboratory experiments (open symbols; pore angle not measured). For a given pore aspect ratio, the tensile strengths from the laboratory experiments are typically larger than those from the numerical experiments (Figure 10b). Because the porosity of the laboratory samples is similar to or greater than the porosity of the numerical samples in Figure 10b (all except the basalt from Mt Etna; Table 5), the higher laboratory tensile strengths in Figure $10 \mathrm{~b}$ is likely the result of the smaller pore diameter of the laboratory samples. The simple comparison of the results from the laboratory and numerical experiments (Figure 10) demonstrates the difficulty in studying the influence of pore geometry (pore size, pore aspect ratio, and pore angle) on the tensile strength of volcanic rocks using natural samples, highlighting the importance of the numerical experiments.

We highlight that our numerical simulations were performed in $2 \mathrm{D}$ and so any comparisons with laboratory experiments should be handled with care. It is known that values 
493 of strength from numerical experiments are typically higher in 2D than 3D (e.g., Laghaei et al., 494 2018). Although 3D numerical experiments, including tensile experiments, can be performed 495 using RFPA (e.g., Zhou et al., 2020; Yuan et al., 2021) they are, at present, too computational 496 expensive to perform systematic studies requiring tens or hundreds of numerical experiments. 497 Finally, we note that there is an initial non-linear part in the laboratory force-displacement 498 curves (Figure 8), typically interpreted as due to the closure of microcracks, that is not observed 499 in the numerical experiments (Figure 4). The absence of this initial non-linear portion can be 500 explained by the absence of microcracks in the numerical samples (Figure 1).
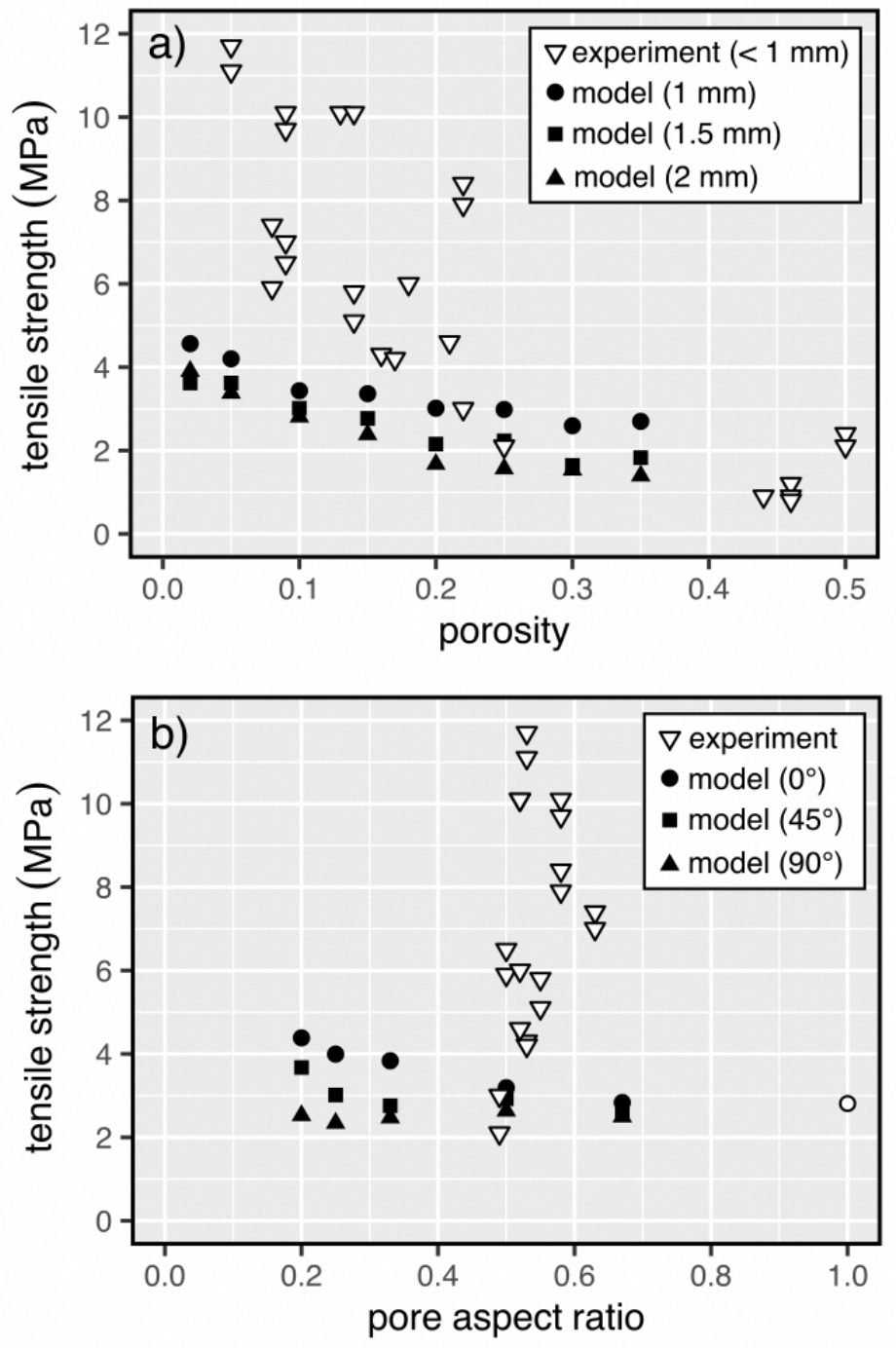
Figure 10. Numerical (filled symbols) and laboratory (open symbols) indirect tensile strength as a function of (a) porosity and (b) pore aspect ratio. In (a), the numerical tensile strengths are for three different pore diameters: $1 \mathrm{~mm}$ (circles), $1.5 \mathrm{~mm}$ (squares), and $2 \mathrm{~mm}$ (triangles); the pore aspect ratio was fixed at 1 (i.e. circular pores) for these numerical experiments. In (b), the numerical tensile strengths are for three different pore angles: $0^{\circ}$ (circles), $45^{\circ}$ (squares), and $90^{\circ}$ (triangles); the porosity and pore diameter (the pore major axis) were fixed at, respectively, 0.1 and $2 \mathrm{~mm}$ for these numerical experiments.

\subsection{Comparisons with previously published laboratory data}

Our new experimental and numerical data show that tensile strength decreases nonlinearly as a function of increasing porosity, in accordance with compiled data from previous studies on volcanic rock (Figure 11). Although our numerical data fit within the scatter of the laboratory data, they typically represent the lowest tensile strength for a given porosity (Figure 11). The most likely explanation for the low numerical tensile strength is that the numerical samples contain pores with diameters much higher (1-2 mm; Figure 1) than volcanic rocks deformed in the laboratory, a microstructural variable shown to influence tensile strength (Figure 6). For example, the mean macropore diameter for the samples deformed for this study was 16-322 $\mu \mathrm{m}$ (Figure 2; Table 3). Other differences between the numerical samples and natural samples include (1) the numerical samples have a uniform pore size (Figure 1), which is not the case for natural samples (Figure 2), (2) the pores in our numerical samples are either circular or elliptical (Figure 1), whereas pores in natural samples can be oddly shaped (Figure 2), (3) volcanic rocks typically contain microcracks (Figure 2), which are not present in the numerical samples (Figure 1), and (4) all of the porosity in our numerical samples is isolated (Figure 1), whereas natural volcanic rocks can contain pores that are connected by other pores, pore throats, and microcracks; Figure 2). 


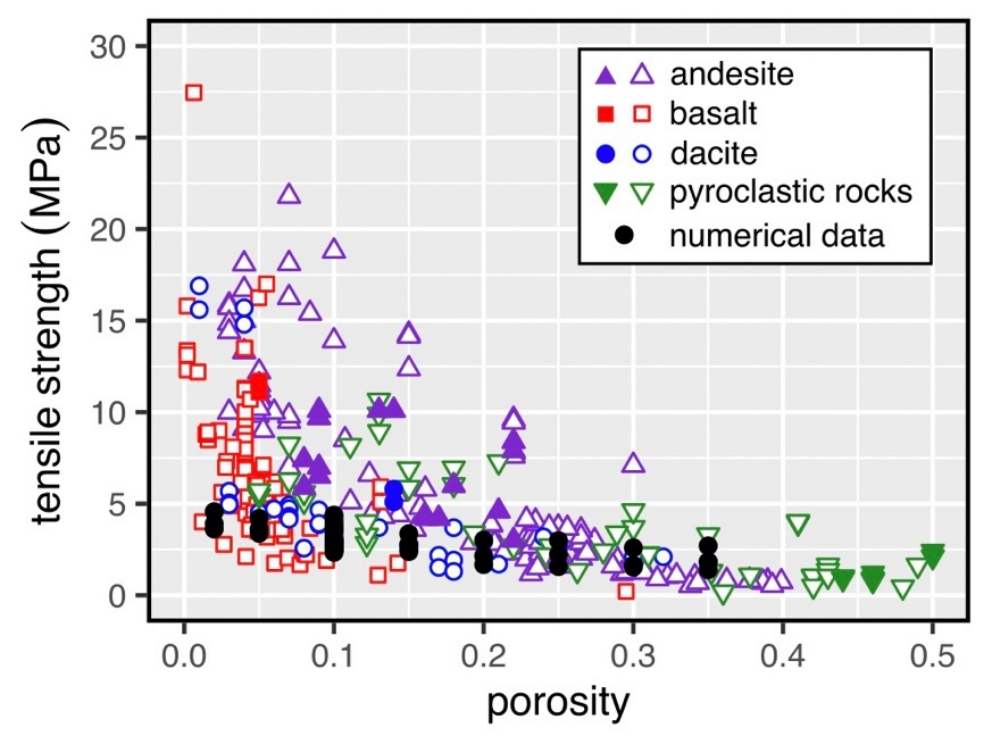

$530 \quad$ Figure 11. Tensile strength as a function of porosity for the numerical (black circles) and 531 laboratory data (filled symbols) unique to this study, and compiled laboratory data from the 532 literature (open symbols). Literature data from: Tuğrul and Gürpinar (1997), Gupta and Rao 533 (2000), Chen et al. (2004), Ersoy and Atici (2007), Kılıç and Teymen (2008), Nara et al. 534 (2010b), Kahraman and Yeken (2010), Graue et al. (2011), Lavallée et al. (2012), Heap et al. 535 (2012), Wedekind et al. (2013), Karakuş and Akatay (2013), Hashiba and Fakui (2015), 536 Siratovich et al. (2015), Fener and Ince (2015), Ündül and Er (2017), Yavuz et al. (2017), 537 Lamb et al. (2017), Malik et al. (2017), Aldeeky and Hattamleh (2018), Zorn et al. (2018), 538 Hornby et al. (2019), Harnett et al. (2019), Moon and Yang (2000), Yasar and Komurlu (2020), and Kendrick et al. (2021).

5414.3 Constitutive models for tensile strength: micromechanical pore crack model The pore-emanating crack model of Sammis and Ashby (1986), which describes an

543 elastic medium populated with circular pores of a uniform radius, has often been employed to 544 better understand the mechanical behaviour and failure of porous rock in compression (e.g., 545 Baud et al., 2014), including volcanic rocks (see Heap and Violay (2021) for a review). 
Although the pore-emanating crack model used here is the 2D empirical and analytical 547 approximation of the full solution (from Zhu et al., 2011), it has been successfully used 548 previously to glean insight on mechanical behaviour and failure of porous rock through 549 comparison with laboratory data (e.g., Baud et al., 2014). An analytical approximation for the $5502 \mathrm{D}$ numerical solution of the pore crack model casts the uniaxial compressive strength, $\sigma_{c}$, as a 551 function of the porosity, $\phi$, the fracture toughness, $K_{I C}$, and the pore radius, $r$, such that (Zhu 552 et al., 2011; Baud et al., 2014):

$$
\sigma_{c}=\frac{1.325}{\phi^{0.414}} \frac{K_{I C}}{\sqrt{\pi r}}
$$

We can use this analytical approximation (Equation (7)) to better understand our tensile strength data by considering the ratio of compressive to tensile strength, $T$, a ratio that is typically between 10 and 30 for rock (Hoek and Brown, 2019). Because the RFPA2D model was calibrated using the glass strength data from Vasseur et al. (2013) (see Table 2 and Heap et al., 2014a), we use the fracture toughness of glass $\left(K_{I C}=0.7\right.$ MPa.m ${ }^{0.5}$; Vasseur et al., 2013; Heap and Violay, 2021) in Equation (7). Figure 12a shows that, using a $\sigma_{c} / T$ of 15 , the modelled curves predicted by the pore crack model are in good agreement with the tensile strength from the numerical experiments for circular pore diameters of 1, 1.5, and $2 \mathrm{~mm}$. In particular, both approaches predict similar increases in tensile strength as a function of decreasing pore size

565 (Figure 12a). However, the tensile strength data from the numerical experiments for non566 circular pores (the datapoints at a porosity of 0.1 ) deviate from the strength predictions from 567 the pore crack model (Figure 12b), due to the assumption of circular pores in the pore crack 568 model (Sammis and Ashby, 1986). 

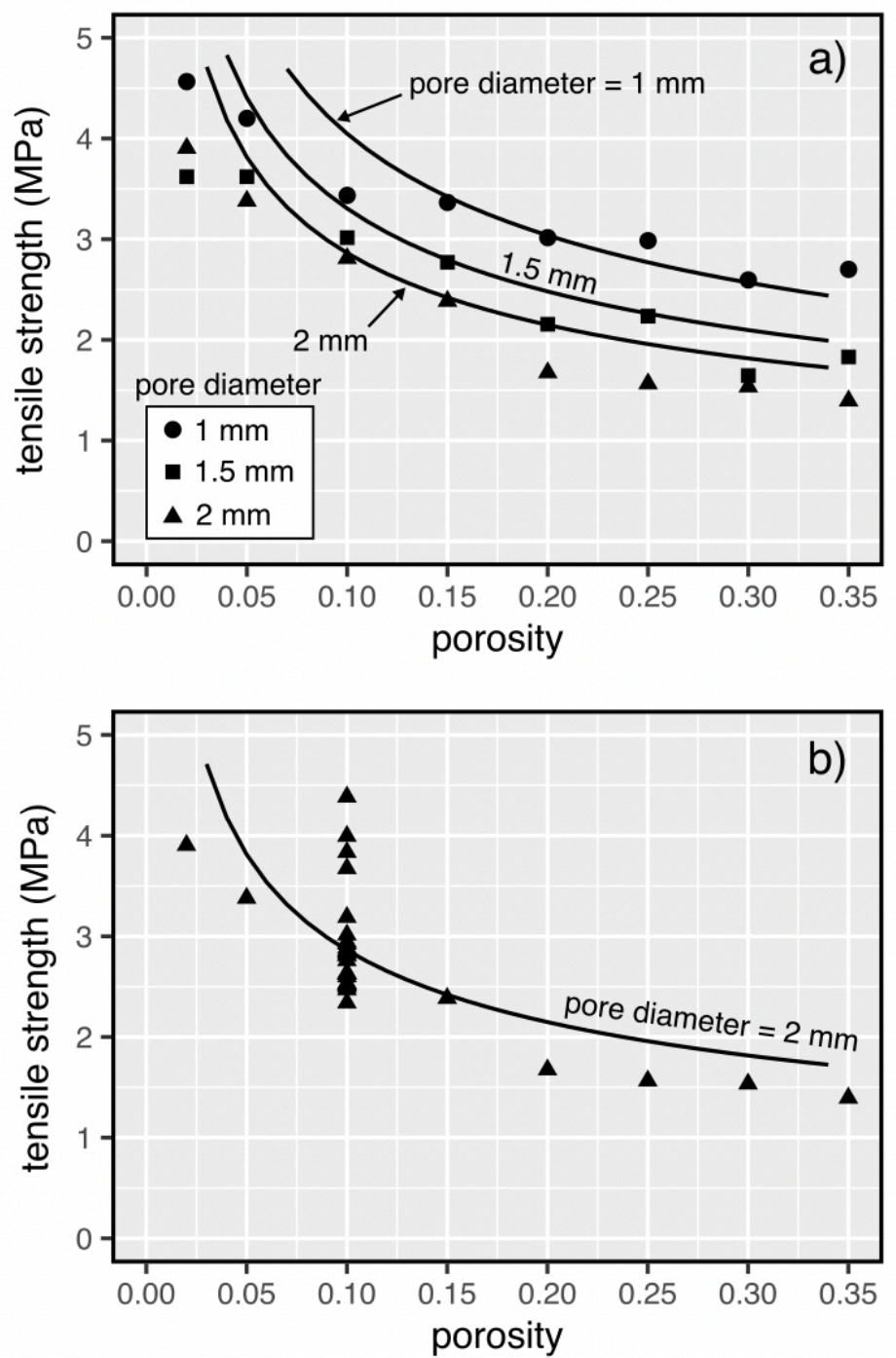

Figure 12. (a) Indirect tensile strength data from the numerical experiments as a function of

572 porosity for three different pore diameters: $1 \mathrm{~mm}$ (circles), $1.5 \mathrm{~mm}$ (squares), and $2 \mathrm{~mm}$

573 (triangles). The pore aspect ratio was fixed at 1 (i.e. circular pores) for these numerical

574 experiments. Solid lines are modelled curves for pore diameters of $1,1.5$, and $2 \mathrm{~mm}$ using

575 Equation (7), assuming a fracture toughness $\left(K_{I C}\right)$ of $0.7 \mathrm{MPa} . \mathrm{m}^{0.5}$, and a ratio of tensile

576 strength to compressive of 1/15. (b) Indirect tensile strength from the numerical experiments

577 as a function of porosity for all the numerical experiments with a pore diameter of $2 \mathrm{~mm}$ (in

578 these numerical experiments the pore aspect ratio varies from 0.2 to 1 and the pore angle

579 varies from 0 to $90^{\circ}$; see Table 4). Solid line is a modelled curve for a pore diameter of $2 \mathrm{~mm}$ 
using Equation (7), assuming a fracture toughness $\left(K_{I C}\right)$ of $0.7 \mathrm{MPa} \cdot \mathrm{m}^{0.5}$, and a ratio of tensile strength to compressive strength of $1 / 15$.

Although the laboratory data (data unique to this study and data compiled from the literature) are characterised by different pore diameters, pore shapes, and pore size distributions, and different values of $K_{I C}$, we can use Equation (7) to bracket the data for different values of $\frac{K_{I C}}{\sqrt{\pi r}}$. We find, again using a $\sigma_{c} / T$ of 15 , that the experimental data can be bracketed by curves for which $\frac{K_{I C}}{\sqrt{\pi r}}$ is equal to 4 and $80 \mathrm{MPa}$, although we note that the experimental data are better described by $\frac{K_{I C}}{\sqrt{\pi r}}=17 \mathrm{MPa}$ (Figure 13). By assuming values for $K_{I C}$, we assess the use of this model for describing the tensile strength of volcanic rocks by exploring whether the pore crack model yields reasonable pore diameter estimates for the compiled dataset. Based on the discussion provided in Heap and Violay (2021), we will assume either the fracture toughness of glass $\left(K_{I C}=0.7 \mathrm{MPa} . \mathrm{m}^{0.5}\right)$ or feldspar $\left(K_{I C}=0.3 \mathrm{MPa} \cdot \mathrm{m}^{0.5}\right)$. When $\frac{K_{I C}}{\sqrt{\pi r}}$ is equal to $4 \mathrm{MPa}$, the value required to describe the samples with the lowest tensile strength (Figure 13), the pore diameter estimates are 3.6 and $19.4 \mathrm{~mm}$ for $K_{I C}$ values of 0.3 and $0.7 \mathrm{MPa} . \mathrm{m}^{0.5}$, respectively. When $\frac{K_{I C}}{\sqrt{\pi r}}$ is equal to $80 \mathrm{MPa}$, the value required to describe the samples with the highest tensile strength (Figure 13), the pore diameter estimates are 8 and $49 \mu \mathrm{m}$ for $K_{I C}$ values of 0.3 and 0.7 MPa.m ${ }^{0.5}$, respectively. Although is it not unlikely that volcanic rocks can be characterised by small pore diameters $(<50 \mu \mathrm{m})$, the pore diameters predicted for the rocks with the lowest tensile strengths (3.6 and $19.4 \mathrm{~mm}$ ) are clearly overestimates. One reason for this overestimate could be that the samples with the lowest tensile strengths, mostly high-porosity pyroclastic rocks, are characterised by lower values of $K_{I C}$ (as discussed in Heap et al., 2015c). When we use a value of $\frac{K_{I C}}{\sqrt{\pi r}}$ that better describes the dataset $\left(\frac{K_{I C}}{\sqrt{\pi r}}=17 \mathrm{MPa}\right)$, we estimate the pore diameter 
603 to be $200 \mu \mathrm{m}$ and $1.1 \mathrm{~mm}$ for $K_{I C}$ values of 0.3 and $0.7 \mathrm{MPa} . \mathrm{m}^{0.5}$, respectively. The pore 604 diameter estimates for $\frac{K_{I C}}{\sqrt{\pi r}}=17 \mathrm{MPa}$, which are within the range typically observed for volcanic 605 rocks measured in the laboratory (see, for example, Heap et al., 2014c), provide confidence that 606 the pore crack model (Equation (7)) can be used to estimate the tensile strength of volcanic rock 607 (using a $\sigma_{c} / T$ of 15 ). The tensile strength of porous volcanic rocks can therefore be 608 approximated using the following relation:

609

$$
T=\frac{1.325}{15 \phi^{0.414}} \frac{K_{I C}}{\sqrt{\pi r}}
$$

612 Care should be taken, however, as the accuracy of tensile strength estimations using Equation 613 (8) may be low if the aspect ratio of the pores differs significantly from unity (Figure 12b).

614

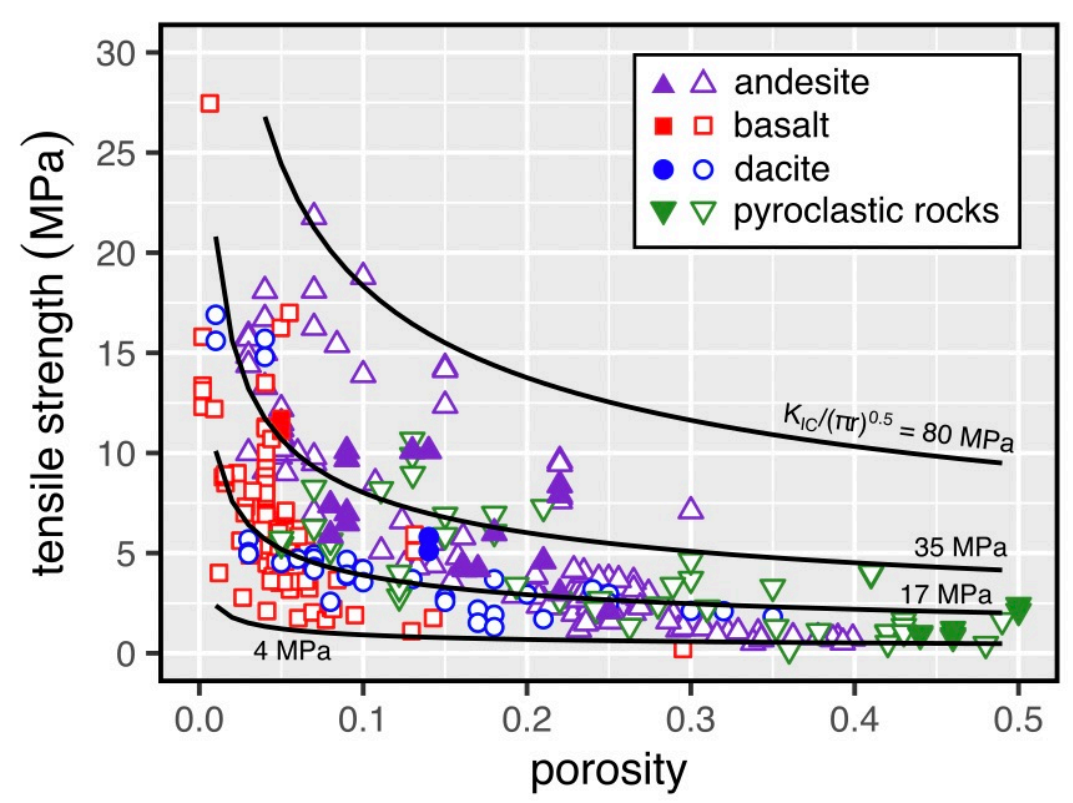

615

616 Figure 13. Laboratory indirect tensile strength as a function of porosity (data from this study 617 (open symbols) and compiled from the literature (filled symbols); see the caption of Figure 11 
618 for the references). Solid lines are modelled curves for $\frac{K_{I C}}{\sqrt{\pi r}}=4,17,35$, and $80 \mathrm{MPa}$ using Equation (7). See text for details.

4.4 Constitutive models for tensile strength: fragmentation models

During ascent through the crust, magma may fragment to form pyroclasts and ash particles. This fragmentation can occur via a range of dynamic processes, dominantly depending on the ascent rate of the magma and the magma material properties (Gonnermann, 2015). Generally, for magmas with a sufficiently high viscosity, $\eta$, such that viscous forces in the melt phase dominate, magma fragmentation is driven by a high bubble gas pressure relative to the magmastatic pressure (e.g., Ichihara et al., 2002), which can cause tensile rupture of the bubble walls. Rapid decompression of the magma can drive bubble gas pressure to rise, resisted by the viscosity of the melt shell, such that the overpressure can rise extremely rapidly (Spieler 2009), and is extant exactly at the fragmentation interval in a rising column of magma (Degruyter et al., 2012).

634 which allow the prediction of the critical pressure drop required to rupture a bubbly magma. In 635 most cases, the simplifying assumption is that the pressure drop and associated gas pressure 636 rise in the bubble is sufficiently rapid that an elastic model for the melt around the bubbles is 637 valid (e.g., Zhang, 1999; Koyaguchi et al., 2008). This is akin to assuming that the shear strain 638 rate in the magma bubble walls induced by the bubble gas expansion is sufficiently high that a 639 melt viscoelastic rheology is pushed to the unrelaxed elastic end-member (cf. Dingwell, 1996; 640 Wadsworth et al., 2018). The consequence of assuming an elastic rheology for the bubble walls 641 is that elasticity theory can be used to derive the critical pressure and rate-dependent parameters 642 are negligible; simplifying the problem significantly. 
644 That is, they consider the response of a single bubble in a finite elastic spherical shell to a rapid 645 decompression, and solve for the critical pressure difference above which a fracture can 646 propagate from the bubble wall through the shell, $\Delta P_{f}$. Fragmentation is therefore considered 647 the point when the shell breaks from edge-to-edge. McBirney and Murase (1970) proposed that 648 $\Delta P_{f}$ was a function of the porosity, $\phi$, via:

649

$$
\Delta P_{f}=\frac{T_{0}(1-1.7 \phi)^{1 / 2}}{\phi}
$$

where $T_{0}$ is an effective characteristic tensile stress. Since the model by McBirney and Murase 653 (1970; Equation (9)), a suite of models has been proposed with similar foundations in elasticity theory, differing in the details of the assumptions made in the derivation approach. Zhang 655 (1999) proposed that:

656

$$
\Delta P_{f}=\frac{2 T_{0}(1-\phi)}{1+2 \phi}
$$

Both Alidibirov (1994) and Koyaguchi et al. (2008) found a solution of the general form:

660

$$
\Delta P_{f}=\frac{2 T_{0}\left(1-\phi^{n}\right)}{a \phi^{n}}
$$

662

663 where Alidibirov (1994) found $n=1 / 3$ and $a=1$, while Koyaguchi et al. (2008) found $n=$ 6641 and $a=3$. Koyaguchi et al. (2008) additionally give a revised fragmentation criterion by 665 taking into account the effective strength at growing crack tips: 


$$
\Delta P_{f}=\frac{2 T_{0}(1-\phi)}{3 \phi \sqrt{\phi^{-1 / 3}-1}}
$$

668

669 In the case of Equations (9) to (12), $\Delta P_{f}$ has a strong dependence on $\phi$ and is clearly dependent

670 on the accurate determination of $T_{0}$.

671 Shock-tube experiments on cold or hot volcanic rocks (Spieler et al., 2004), and on

672 silicate melts with (Martel et al., 2001) or without (Martel et al., 2000) crystalline phases have

673 confirmed that $\Delta P_{f}$ is a strong function of $\phi$. Empirical correlation by Spieler et al. (2004)

674 suggested that the simplest form of this dependence of $\Delta P_{f}$ on $\phi$ was $\Delta P_{c}=T_{0} / \phi$ (note that

675 their original correlation was simply $\Delta P \propto 1 / \phi)$, which matches their data reasonably well as

676 a lower-bound. The more rigorous predictions of $\Delta P_{f}$ given by Equations (9) to (12) match the

677 experimental data reasonably well, as long as $T_{0}$ is treated as a fitting parameter. In Figure $14 \mathrm{a}$

678 we show the five models given here (Equations (9) to (12) and the lower-bound $\Delta P_{f}=T_{0} / \phi$ )

679 where we take $T_{0}=1 \mathrm{MPa}$ for illustrative purposes. Koyaguchi et al. (2008) fit for $T_{0}$ using an

680 early dataset of shock-tube fragmentation tests (Spieler et al., 2004) and found that, depending

681 on the model used, $T_{0}$ ranged from 1.461 to $11.98 \mathrm{MPa}$. 

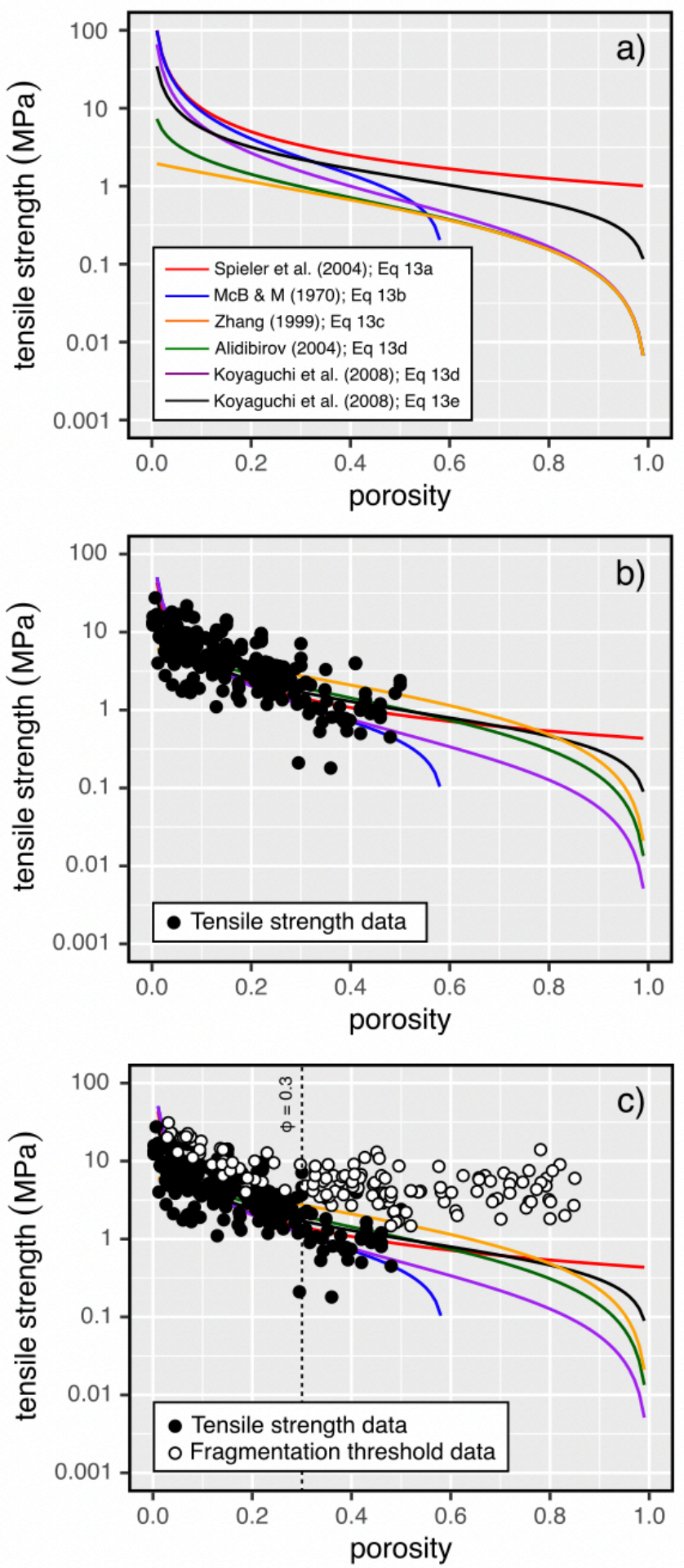

Figure 14. (a) Modelled tensile strength as a function of porosity using Equations (9) to (12) and the Spieler et al. (2004) scaling $\left(\Delta P_{f}=T_{0} / \phi\right)$, where we take $T_{0}=1 \mathrm{MPa}$ for illustrative purposes. It is assumed here that $T \approx \Delta P_{f}$. (b) Modelled ensile strength as a function of porosity using Equation (13), where we use the best-fit solution of Equation (13) 
to the compiled laboratory data for the tensile strength of volcanic rocks (black circles; references given in Figure 11). The best-fit values of $T_{0}$ for each equation are provided in Table 6. (b) Modelled ensile strength as a function of porosity using Equation (13), where we use the best-fit solution of Equation (13) to the compiled laboratory data for the tensile strength (black circles; references given in Figure 11) and fragmentation threshold of volcanic rocks (white circles; data from Spieler et al. (2004), Kueppers et al. (2006), Scheu et al. (2006), Mueller et al. (2008), Alatorre-Ibargüengoitia et al. (2010), Kremers et al. (2010), Richard et al. (2013), Mayer et al. (2015, 2016), Montanaro et al. (2016)). A line is drawn at a porosity of 0.3 to indicate the porosity at which the models (i.e., Equation (13)) no longer follow the fragmentation threshold data.

697

All of the models described above by Equations (9) to (12) and by the Spieler et al. 699 (2004) scaling $\Delta P_{f}=T_{0} / \phi$, are micromechanical models for what is a tensile bursting of an array of gas-filled solid elastic shells under a given external tensile pressure. This framework is therefore, conceptually akin to micromechanical models for the rupture of porous solids under a tensile load (McBirney and Murase, 1970). We therefore suggest that $\Delta P_{f}$ could be interpreted as a critical bulk tensile strength of the porous rock or magma, which accounts for the stress concentration around the pores or bubbles. This is akin to saying that Equations (9) to (12) and the Spieler et al. (2004) scaling can be recast as:

706

$$
T \approx \frac{T_{0}}{\phi}
$$

$$
T \approx \frac{T_{0}(1-1.7 \phi)^{\frac{1}{2}}}{\phi}
$$




$$
T \approx \frac{2 T_{0}(1-\phi)}{1+2 \phi}
$$

$$
T \approx \frac{2 T_{0}\left(1-\phi^{n}\right)}{a \phi^{n}}
$$

$$
T \approx \frac{2 T_{0}(1-\phi)}{3 \phi \sqrt{\phi^{-1 / 3}-1}}
$$

In Figure $14 \mathrm{~b}$ we present the best-fit solution of Equation (13) to the compiled data for

$T(\phi)$ measured for volcanic rocks, and for our numerical samples for which the pores were circular. The fitting is performed by allowing $T_{0}$ to vary freely, and by minimising the sum of square residuals between the logarithm of the data points and the logarithm of each model result at the same porosity (fit results in Table 6). We find values of $T_{0}$ that range from 0.43 to 3.14 MPa for the compiled tensile strength dataset, lower than those typically found when fitting for 723 fragmentation data from shock-tube experiments ( $T_{0}$ ranged from 1.461 to $11.98 \mathrm{MPa}$ in Koyaguchi et al., 2008). Based on the good description of Equation (13) to the compiled tensile strength data for volcanic rocks, we consider that Equation (13) can be used to approximate the tensile strength of volcanic rocks using the values of $T_{0}$ provided in Table 6 . As for Equation (8) above, the accuracy of tensile strength estimations using Equation (13) may be low if the aspect ratio of the pores differs significantly from unity (Figure 12b).

\begin{tabular}{|c|c|c|}
\hline Model & $\boldsymbol{T}_{\mathbf{0}} \mathbf{( M P a )}$ & Goodness of fit \\
\hline $\begin{array}{c}\text { Spieler et al. (2004) } \\
\text { Equation (13a) }\end{array}$ & 0.43 & 0.9948 \\
\hline $\begin{array}{c}\text { McBirney and Murase } \\
\text { (1970) } \\
\text { Equation (13b) }\end{array}$ & 0.51 & 0.9939 \\
\hline Zhang (1999) & & 0.9961 \\
\hline
\end{tabular}




\begin{tabular}{|c|c|c|}
\hline Equation (13c) & & \\
\hline $\begin{array}{c}\text { Alidibirov (1994) } \\
\text { Equation (13d) } \\
(n=1 / 3 ; a=1)\end{array}$ & 2.00 & 0.9970 \\
\hline $\begin{array}{c}\text { Koyaguchi et al. (2008) } \\
\text { Equation (13d) } \\
(n=1 ; a=3)\end{array}$ & 0.76 & 0.9939 \\
\hline $\begin{array}{c}\text { Koyaguchi et al. }(2008) \\
\text { Equation }(13 \mathrm{e})\end{array}$ & 0.77 & 0.9961 \\
\hline
\end{tabular}

730

Table 6. Best-fit values for the effective characteristic tensile stress, $T_{0}$, and the associated goodness of fit values, for the compiled laboratory data (see Figure 14b and 14c).

We also compile published data from shock-tube experiments for rock (cold) and magma (hot) fragmentation thresholds under rapid decompression (Spieler et al., 2004; Kueppers et al., 2006; Scheu et al., 2006; Mueller et al., 2008; Alatorre-Ibargüengoitia et al., 2010; Kremers et al., 2010; Richard et al., 2013; Mayer et al., 2015, 2016; Montanaro et al., 2016). In Figure 14c, we show these data together with compiled volcanic rock tensile strength data, and the models from Equation (13) using the best-fit values of $T_{0}$ from Table 6 (where the fits were performed against the compiled tensile strength data only). We note that the data from shock-tube experiments approaches the data for direct tensile strength tests on volcanic rocks, and the associated model fits at low porosity, but diverge at high porosity. Indeed, at high porosity, the tensile strength data cluster around an apparently porosity independent value of tensile strength, and the reduction in the critical decompression required to fragment the samples becomes approximately constant, in contrast with the model predictions (Figure 14c). Mueller et al. (2008) suggested that positive deviations from model predictions, such as shown here (Figure 14c), could be the result of permeable leakage of overpressure from connected and permeable pore space during decompression. This permeable leakage invalidates the model 
predictions (Equation (13)) which are strictly based on closed pore geometries. Mueller et al. (2008) provided an empirical correction to the fragmentation (or tensile strength) laws from Equation (13), which captured this deviation. We find it compelling that the data from the shock-tube experiments diverges strongly from the direct tensile strength test data for volcanic rocks, and from the model predictions, for $\phi \gtrsim 0.2-0.3$. In Figure $14 \mathrm{c}$, we show a vertical threshold at $\phi=0.3$, above which most volcanic rocks are considered to have a high permeability (Mueller et al., 2005; Farquharson et al., 2015). It is conceivable that the shocktube experiments provide valid one-dimensional approximations to a direct tensile strength test when $\phi<0.3$, but that permeable leakage affects these measurements at $\phi>0.3$. It is therefore of first-order importance to constrain the permeability of volcanic rocks and magmas to understand rock and magma fragmentation (Mueller et al., 2008). We further note that, below a porosity of 0.3 , laboratory measurements of tensile strength, measurements much less involved than fragmentation experiments, will well approximate the fragmentation threshold of volcanic rocks and magmas.

4.5 Implications for magma chamber rupture, dyking, and magma chamber volume estimates The rupture of a magma chamber, allowing for dyke initiation and propagation, is thought to occur when the following expression is satisfied (Gudmundsson, 2006):

where $P_{1}$ is the lithostatic pressure, $P_{e}$ is the magma overpressure $\left(P_{e}=P_{m}-P_{1}\right.$, where $P_{m}$ is the magma pressure), $\sigma_{3}$ is the minimum principal compressive stress, and $T$ is the tensile strength of the host rock. Estimates of magma overpressures required for magma chamber rupture therefore depend on robust values of the tensile strength of the host rock. Our laboratory 
and numerical data highlight that porosity and pore geometry (pore aspect ratio and pore angle) can greatly influence the tensile strength of rocks (Figures 5, 6, 7, and 9). For example, at a porosity of 0.25 , tensile strength can be reduced from 3 to $1.5 \mathrm{MPa}$ as the pore diameter is increased from 1 to $2 \mathrm{~mm}$ (Figure 6). Therefore, if possible, these factors should be considered when estimating the tensile strength of rock to provide estimates of the magma overpressure required for magma chamber rupture.

Once the magma chamber has been ruptured, the simplest condition for propagation of a dyke through the host rock is that the magma pressure, $P_{m}$, exceeds the minimum principal compressive stress, $\sigma_{3}$, the tensile strength of the host rock, $T$, and the pressure required to hold open the resultant crack of a given width, $P_{s}$ (i.e. $P_{m}>\sigma_{3}+T+P_{s}$ ). If we take the magma overpressure to be $\Delta P_{m}=P_{m}-\sigma_{3}$, then this dyke propagation condition is (Gudmundsson, 1983a; 1983b):

for which $E$ is the Young's modulus of the host rock, $W$ and $L$ are a dyke width and length, respectively, and $v$ is the Poisson's ratio of the host rock. Equation (15) shows that the tensile strength of the host rock through which the dyke must propagate exerts a first-order control on the overpressures required in dyke advance, and so estimates of magma overpressure rely on robust values of the tensile strength of the host rock.

$$
\Delta P_{m}=T+P_{s}=T+\frac{E}{2\left(1-v^{2}\right)} \frac{W}{L}
$$

Finally, the volume of a magma chamber, $V_{m}$, can be estimated using the total erupted volume, $V_{e}$, the tensile strength of the host rock, $T$, and the compressibility of the host rock and magma, $\beta_{r}$ and $\beta_{m}$, respectively (Gudmundsson, 1987; Browning et al., 2015): 


$$
V_{m}=\frac{V_{e}}{T\left(\beta_{m}+\beta_{r}\right)}
$$

799

800 Taking $\beta_{r}$ and $\beta_{m}$ as, respectively, $3.0 \times 10^{-11}$ and $1.25 \times 10^{-10} \mathrm{~Pa}^{-1}$ (Gudmundsson, 1987;

801 Browning et al., 2015) and assuming values of $V_{e}$ of $5 \times 10^{7}, 2.5 \times 10^{8}, 1 \times 10^{9} \mathrm{~m}^{3}(0.05,0.25$,

802 and $1 \mathrm{~km}^{3}$, respectively), we can investigate the influence of $T$ on estimations of magma

803 chamber volume and, in turn, on magma chamber radius (assuming a spherical magma 804 chamber). We find that small changes in tensile strength at $T<5 \mathrm{MPa}$ result in large changes 805 in both magma chamber volume and radius (Figure 15). At $T>5 \mathrm{MPa}$, small changes in tensile 806 strength result in relatively small changes in magma chamber volume and radius (Figure 15).

807 Since the majority of volcanic rocks have a tensile strength below $5 \mathrm{MPa}$ (Figure 11), it is 808 therefore important to carefully consider the tensile strength used in Equation (16). 

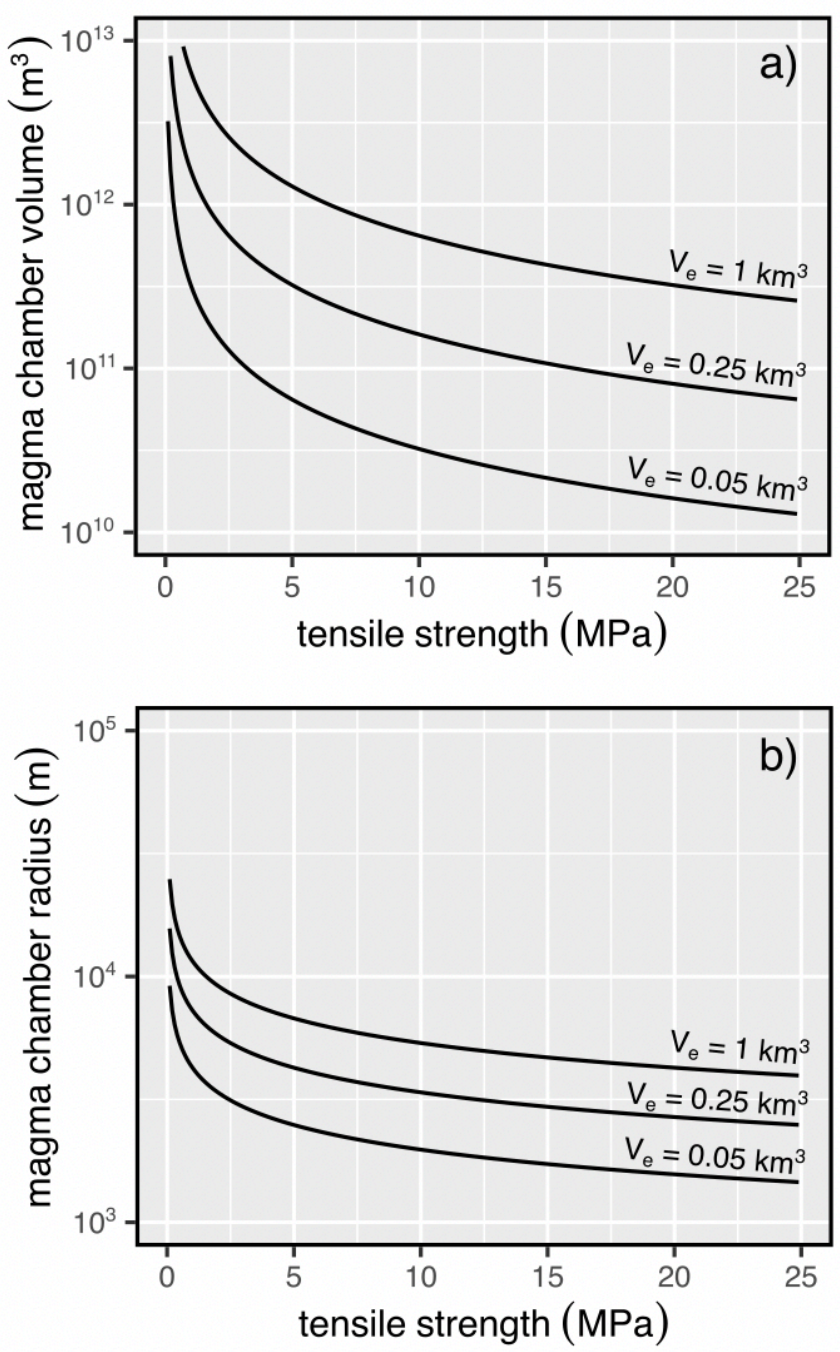

811 Figure 15. Magma chamber volume required to produce an eruption of a given size (a) and

812 radius (b) as a function of host-rock tensile strength, using Equation (16). Taking $\beta_{r}$ and $\beta_{m}$ as, respectively, $3.0 \times 10^{-11}$ and $1.25 \times 10^{-10} \mathrm{~Pa}^{-1}$ and assuming values of $V_{e}$ of $5 \times 10^{7}, 2.5 \times$ $10^{8}, 1 \times 10^{9} \mathrm{~m}^{3}\left(0.05,0.25\right.$, and $1 \mathrm{~km}^{3}$, respectively)

817 strengths used in the above equations were taken from in-situ tensile strengths from borehole 818 measurements (e.g., Haimson and Rummel, 1982). However, in the likely case that borehole 819 data are not available, values of tensile strength for Equations (14) to (16) will rely on (1) 820 laboratory measurements of tensile strength performed on site-specific samples, (2) tensile 
strengths estimated using the porosity of site-specific samples and Equation (13) or, if KIC and the pore radius are also known, Equation (8), and (3) values of tensile strength for the main

823 lithology of the studied area taken from previous experimental studies (Figure 11). 824 Alternatively, authors could use borehole data collected at other sites (e.g., Haimson and 825 Rummel, 1982; Amadei and Stephansson, 1997). Site-specific borehole measurements could 826 be considered the most appropriate data to use in Equations (14) to (16), as they are performed 827 at non-zero confining pressures (i.e. at depth) and likely better represent the lengthscale of 828 interest. Tensile strength is thought to be affected by confining pressure (e.g., Wu et al., 2016;

829 Lan et al., 2019; Li et al., 2019) and lengthscale (e.g., Schultz, 1995; Jónsson, 2012), although 830 more data, especially for volcanic rocks, are required to better understand their influence on 831 tensile strength. Whatever the preferred method to measure or estimate values of tensile 832 strength for Equations (14) to (16), we highlight that the accuracy of this value will determine 833 the accuracy of, for example, predictions of the magma overpressures required for rupture and 834 dyke propagation (Equations (14) and (15)) and magma volume estimates (Equation (16)). 835 Finally, we note that not all magma chambers are located within volcanic rock. For example, 836 the magma chamber within Cadillac Mountain in Maine (USA) was located with plutonic and 837 sedimentary rocks (Wiebe et al., 2021), and the magma chambers of many volcanoes are 838 thought to be located in carbonate rocks, such as Mt Etna (Heap et al., 2013; Wiesmaier et al., 839 2015) and Merapi volcano (Deegan et al., 2010; Troll et al., 2012). In such scenarios, modellers 840 may want to use values of tensile strength for plutonic or sedimentary rocks, rather than the 841 data for volcanic rocks compiled here (Figure 11). However, we consider the salient 842 conclusions of our study, such as the influence of porosity and pore geometry, as relevant for a 843 wide range of rock types, not just volcanic rocks. 

important input parameter in a range of volcano models, depends to a first-order on porosity and pore size. Our numerical experiments have also highlighted a second-order role for pore aspect ratio and pore angle in dictating the tensile strength of volcanic rocks. These latter numerical experiments highlight that the tensile strength of volcanic rock can be anisotropic.

851 Our numerical data are in general agreement with new and compiled laboratory data for the 852 tensile strength of volcanic rocks. Comparison of the numerical and laboratory data highlights 853 that, due to the natural heterogeneity and variability of natural volcanic rocks, discerning the 854 role of pore geometry on the tensile strength of volcanic rocks using laboratory experiments 855 alone would represent a significant challenge. Although the theoretical and semi-empirical 856 constitutive equations provided here, i.e. Equations (8) and (13), to do not take pore aspect ratio 857 or angle into account, parameters that we show influence tensile strength, they provide a means 858 to estimate the tensile strength of volcanic rocks using rock physical properties that are 859 relatively straightforward to measure in the laboratory and the field, such as porosity. These 860 results can now help to better equip volcano modellers that require estimations of the tensile 861 strength of volcanic rocks for their models. Although we focused here on volcanic rocks, we 862 highlight that the salient conclusions of this study are likely relevant for a wide range of rock 863 types, not just volcanic rocks.

\section{Acknowledgements}

We thank Bertrand Renaudié for preparing the experimental samples. T. Xu 867 acknowledges funding from the National Natural Science Foundation of China (grant number 868 51974062). M. Heap acknowledges support from the Institut Universitaire de France (IUF). 869 The authors would like to thank John Browning and Stephan Kolzenburg for constructive 870 comments that helped improve this manuscript. 


\section{CRediT author statement}

873 M.J. Heap - Conceptualization; Formal analysis; Investigation; Writing - Original Draft;

874 Visualization; Supervision; Project administration; Funding acquisition

875 F.B. Wadsworth - Conceptualization; Formal analysis; Writing - Review \& Editing

876 Z. Heng - Methodology; Software; Investigation

877 T. Xu - Methodology; Software; Investigation; Resources; Writing - Review \& Editing;

878 Supervision; Funding acquisition

879 L. Griffiths - Conceptualization; Methodology; Resources; Writing - Review \& Editing

880 A. Aguilar Velasco - Investigation

881 E. Vairé - Investigation

882 M. Vistour - Investigation

883 T. Reuschlé - Methodology; Writing - Review \& Editing

884 V.R. Troll - Resources; Writing - Review \& Editing

885 F.M. Deegan - Resources; Writing - Review \& Editing

886 C.-a. Tang - Methodology; Software; Resources; Writing - Review \& Editing

887

\section{References}

Alatorre-Ibargüengoitia, M. A., Scheu, B., Dingwell, D. B., Delgado-Granados, H., \& Taddeucci, J. (2010). Energy consumption by magmatic fragmentation and pyroclast ejection during Vulcanian eruptions. Earth and Planetary Science Letters, 291(1-4), 6069.

Alidibirov, M. A. (1994). A model for viscous magma fragmentation during volcanic blasts. Bulletin of Volcanology, 56(6), 459-465.

Aldeeky, H., \& Al Hattamleh, O. (2018). Prediction of engineering properties of basalt rock in Jordan using ultrasonic pulse velocity test. Geotechnical and Geological Engineering, 36(6), 3511-3525.

Amadei, B., \& Stephansson, O. (1997). Rock stress and its measurement. Springer Science \& Business Media.

Aydin, A., \& DeGraff, J. M. (1988). Evolution of polygonal fracture patterns in lava flows. Science, 239(4839), 471-476. 
Baud, P., Wong, T. F., \& Zhu, W. (2014). Effects of porosity and crack density on the compressive strength of rocks. International Journal of Rock Mechanics and Mining Sciences, 67, 202-211.

Bieniawski, Z. T., \& Hawkes, I. (1978). Suggested methods for determining tensile strength of rock materials. International Journal of Rock Mechanics and Mining Sciences, 15(3), 99103.

Browning, J., Drymoni, K., \& Gudmundsson, A. (2015). Forecasting magma-chamber rupture at Santorini volcano, Greece. Scientific Reports, 5(1), 1-8.

Browning, J., Meredith, P., \& Gudmundsson, A. (2016). Cooling-dominated cracking in thermally stressed volcanic rocks. Geophysical Research Letters, 43(16), 8417-8425.

Bubeck, A., Walker, R. J., Healy, D., Dobbs, M., \& Holwell, D. A. (2017). Pore geometry as a control on rock strength. Earth and Planetary Science Letters, 457, 38-48.

Chen, T. C., Yeung, M. R., \& Mori, N. (2004). Effect of water saturation on deterioration of welded tuff due to freeze-thaw action. Cold Regions Science and Technology, 38(2-3), 127-136.

Clynne, M. A., \& Muffler, L. P. (2017). Geologic field-trip guide to the Lassen segment of the Cascades Arc, northern California (No. 2017-5022-K2). US Geological Survey.

Daoud, A., Browning, J., Meredith, P. G., \& Mitchell, T. M. (2020). Microstructural Controls on Thermal Crack Damage and the Presence of a Temperature-Memory Effect During Cyclic Thermal Stressing of Rocks. Geophysical Research Letters, 47(19), e2020GL088693.

Deegan, F. M., Troll, V. R., Freda, C., Misiti, V., Chadwick, J. P., McLeod, C. L., \& Davidson, J. P. (2010). Magma-carbonate interaction processes and associated CO2 release at Merapi Volcano, Indonesia: insights from experimental petrology. Journal of Petrology, 51(5), 1027-1051.

Degruyter, W., Bachmann, O., Burgisser, A., \& Manga, M. (2012). The effects of outgassing on the transition between effusive and explosive silicic eruptions. Earth and Planetary Science Letters, 349, 161-170.

Dingwell, D. B. (1996). Volcanic Dilemma--Flow or Blow? Science, 273(5278), 1054-1055.

Ersoy, A., \& Atici, U. (2007). Correlation of P and S-Waves with Cutting Specific Energy and Dominant Properties of Volcanic and Carbonate Rocks. Rock Mechanics and Rock Engineering, 40(5), 491-504.

Farquharson, J., Heap, M. J., Varley, N. R., Baud, P., \& Reuschlé, T. (2015). Permeability and porosity relationships of edifice-forming andesites: a combined field and laboratory study. Journal of Volcanology and Geothermal Research, 297, 52-68.

Farquharson, J. I., Heap, M. J., \& Baud, P. (2016). Strain-induced permeability increase in volcanic rock. Geophysical Research Letters, 43(22), 11-603.

Farquharson, J. I., Baud, P., \& Heap, M. J. (2017). Inelastic compaction and permeability evolution in volcanic rock. Solid Earth, 8(2), 561-581.

Fener, M., \& Ince, I. (2015). Effects of the freeze-thaw (F-T) cycle on the andesitic rocks (Sille-Konya/Turkey) used in construction building. Journal of African Earth Sciences, 109, 96-106.

Gonnermann, H. M. (2015). Magma fragmentation. Annual Review of Earth and Planetary Sciences, 43, 431-458.

Griffiths, L., Heap, M. J., Xu, T., Chen, C.-f., \& Baud, P. (2017). The influence of pore geometry and orientation on the strength and stiffness of porous rock. Journal of Structural Geology, 96, 149-160.

Graue, B., Siegesmund, S., \& Middendorf, B. (2011). Quality assessment of replacement stones for the Cologne Cathedral: mineralogical and petrophysical requirements. Environmental Earth Sciences, 63(7-8), 1799-1822. 
Gudmundsson, A. (1983a). Form and dimensions of dykes in eastern Iceland. Tectonophysics, 95(3-4), 295-307.

Gudmundsson, A. (1983b). Stress estimates from the length/width ratios of fractures. Journal of structural geology, 5(6), 623-626.

Gudmundsson, A. (1987). Formation and mechanics of magma reservoirs in Iceland. Geophysical Journal International, 91(1), 27-41.

Gudmundsson, A. (2006). How local stresses control magma-chamber ruptures, dyke injections, and eruptions in composite volcanoes. Earth-Science Reviews, 79(1-2), 1-31.

Gupta, A. S., \& Rao, K. S. (2000). Weathering effects on the strength and deformational behaviour of crystalline rocks under uniaxial compression state. Engineering Geology, 56(3-4), 257-274.

Haimson, B. C., \& Rummel, F. (1982). Hydrofracturing stress measurements in the Iceland research drilling project drill hole at Reydarfjordur, Iceland. Journal of Geophysical Research: Solid Earth, 87(B8), 6631-6649.

Harnett, C. E., Thomas, M. E., Purvance, M. D., \& Neuberg, J. (2018). Using a discrete element approach to model lava dome emplacement and collapse. Journal of Volcanology and Geothermal Research, 359, 68-77.

Harnett, C. E., Kendrick, J. E., Lamur, A., Thomas, M. E., Stinton, A., Wallace, P. A., ... \& Lavallée, Y. (2019). Evolution of mechanical properties of lava dome rocks across the 1995-2010 eruption of Soufrière Hills volcano, Montserrat. Frontiers in Earth Science, $7,7$.

Hashiba, K., \& Fukui, K. (2015). Effect of water on the deformation and failure of rock in uniaxial tension. Rock Mechanics and Rock Engineering, 48(5), 1751-1761.

Heap, M. J., Lavallée, Y., Laumann, A., Hess, K. U., Meredith, P. G., \& Dingwell, D. B. (2012). How tough is tuff in the event of fire? Geology, 40(4), 311-314.

Heap, M. J., Mollo, S., Vinciguerra, S., Lavallée, Y., Hess, K. U., Dingwell, D. B., ... \& Iezzi, G. (2013). Thermal weakening of the carbonate basement under Mt. Etna volcano (Italy): implications for volcano instability. Journal of volcanology and geothermal research, 250, 42-60.

Heap, M. J., Xu, T., \& Chen, C.-f. (2014a). The influence of porosity and vesicle size on the brittle strength of volcanic rocks and magma. Bulletin of Volcanology, 76(9), 1-15.

Heap, M. J., Baud, P., Meredith, P. G., Vinciguerra, S., \& Reuschlé, T. (2014b). The permeability and elastic moduli of tuff from Campi Flegrei, Italy: implications for ground deformation modelling. Solid Earth, 5(1), 25-44.

Heap, M. J., Lavallée, Y., Petrakova, L., Baud, P., Reuschlé, T., Varley, N. R., \& Dingwell, D. B. (2014c). Microstructural controls on the physical and mechanical properties of edificeforming andesites at Volcán de Colima, Mexico. Journal of Geophysical Research: Solid Earth, 119(4), 2925-2963.

Heap, M. J., Xu, T., Kushnir, A. R., Kennedy, B. M., \& Chen, C.-f. (2015a). Fracture of magma containing overpressurised pores. Journal of Volcanology and Geothermal Research, 301, 180-190.

Heap, M. J., Farquharson, J. I., Baud, P., Lavallée, Y., \& Reuschlé, T. (2015b). Fracture and compaction of andesite in a volcanic edifice. Bulletin of volcanology, 77(6), 1-19.

Heap, M. J., Farquharson, J. I., Wadsworth, F. B., Kolzenburg, S., \& Russell, J. K. (2015c). Timescales for permeability reduction and strength recovery in densifying magma. Earth and Planetary Science Letters, 429, 223-233.

Heap, M. J., Wadsworth, F. B., Xu, T., Chen, C.-f., \& Tang, C.-a. (2016). The strength of heterogeneous volcanic rocks: a 2D approximation. Journal of Volcanology and Geothermal Research, 319, 1-11. 
Heap, M., Kushnir, A., Griffiths, L., Wadsworth, F., Marmoni, G. M., Fiorucci, M., ... \& Reuschlé, T. (2018). Fire resistance of the Mt. Epomeo Green Tuff, a widely-used building stone on Ischia Island (Italy). Volcanica, 1(1), 33-48.

Heap, M. J., Tuffen, H., Wadsworth, F. B., Reuschlé, T., Castro, J. M., \& Schipper, C. I. (2019a). The permeability evolution of tuffisites and implications for outgassing through dense rhyolitic magma. Journal of Geophysical Research: Solid Earth, 124(8), 82818299.

Heap, M. J., Troll, V. R., Kushnir, A. R., Gilg, H. A., Collinson, A. S., Deegan, F. M., ... \& Walter, T. R. (2019b). Hydrothermal alteration of andesitic lava domes can lead to explosive volcanic behaviour. Nature Communications, 10(1), 1-10.

Heap, M.J., and Violay, M.E.S. (2021). The mechanical behaviour and failure modes of volcanic rocks: a review. Bulletin of Volcanology, 83, 33 https://doi.org/10.1007/s00445021-01447-2.

Heap M.J., Baumann, T., Gilg, H.A., Kolzenburg, S., Ryan, A., Villeneuve, M., Russell, J.K., Kennedy, L., Rosas-Carbajal, M., \& Clynne M. (2021) Hydrothermal alteration can result in pore pressurization and volcano instability. Geology, 49, https://doi.org/10.1130/G49063.1.

Heiken, G., Wohletz, K., \& Eichelberger, J. (1988). Fracture fillings and intrusive pyroclasts, Inyo Domes, California. Journal of Geophysical Research: Solid Earth, 93(B5), 43354350.

Hoek, E., \& Brown, E. T. (2019). The Hoek-Brown failure criterion and GSI-2018 edition. Journal of Rock Mechanics and Geotechnical Engineering, 11(3), 445-463.

Holohan, E. P., Sudhaus, H., Walter, T. R., Schöpfer, M. P., \& Walsh, J. J. (2017). Effects of host-rock fracturing on elastic-deformation source models of volcano deflation. Scientific reports, 7(1), 1-12.

Hornby, A. J., Lavallée, Y., Kendrick, J. E., De Angelis, S., Lamur, A., Lamb, O. D., ... \& Chigna, G. (2019). Brittle-ductile deformation and tensile rupture of dome lava during inflation at Santiaguito, Guatemala. Journal of Geophysical Research: Solid Earth, 124(10), 10107-10131.

Ichihara, M., Rittel, D., \& Sturtevant, B. (2002). Fragmentation of a porous viscoelastic material: Implications to magma fragmentation. Journal of Geophysical Research: Solid Earth, 107(B10), ECV-8.

Jónsson, S. (2012). Tensile rock mass strength estimated using InSAR. Geophysical Research Letters, 39(21).

Kahraman, S., \& Yeken, T. (2010). Electrical resistivity measurement to predict uniaxial compressive and tensile strength of igneous rocks. Bulletin of Materials Science, 33(6), 731-735.

Karakuş, A., \& Akatay, M. (2013). Determination of basic physical and mechanical properties of basaltic rocks from P-wave velocity. Nondestructive Testing and Evaluation, 28(4), 342-353.

Kendrick, J. E., Schaefer, L. N., Schauroth, J., Bell, A. F., Lamb, O. D., Lamur, A., ... \& Kennedy, B. M. (2021). Physical and mechanical rock properties of a heterogeneous volcano: the case of Mount Unzen, Japan. Solid Earth, 12(3), 633-664.

Kilıç, A., \& Teymen, A. (2008). Determination of mechanical properties of rocks using simple methods. Bulletin of Engineering Geology and the Environment, 67(2), 237.

Koyaguchi, T., Scheu, B., Mitani, N. K., \& Melnik, O. (2008). A fragmentation criterion for highly viscous bubbly magmas estimated from shock tube experiments. Journal of Volcanology and Geothermal Research, 178(1), 58-71. 
Kremers, S., Scheu, B., Cordonnier, B., Spieler, O., \& Dingwell, D. B. (2010). Influence of decompression rate on fragmentation processes: An experimental study. Journal of Volcanology and Geothermal Research, 193(3-4), 182-188.

Kueppers, U., Scheu, B., Spieler, O., \& Dingwell, D. B. (2006). Fragmentation efficiency of explosive volcanic eruptions: A study of experimentally generated pyroclasts. Journal of Volcanology and Geothermal Research, 153(1-2), 125-135.

Kushnir, A. R., Martel, C., Champallier, R., \& Arbaret, L. (2017). In situ confirmation of permeability development in shearing bubble-bearing melts and implications for volcanic outgassing. Earth and Planetary Science Letters, 458, 315-326.

Laghaei, M., Baghbanan, A., Hashemolhosseini, H., \& Dehghanipoodeh, M. (2018). Numerical determination of deformability and strength of 3D fractured rock mass. International Journal of Rock Mechanics and Mining Sciences, 110, 246-256.

Lamb, O. D., De Angelis, S., Wall, R. J., Lamur, A., Varley, N. R., Reyes-Dávila, G., ... \& Lavallée, Y. (2017). Seismic and experimental insights into eruption precursors at Volcán de Colima. Geophysical Research Letters, 44(12), 6092-6100.

Lamur, A., Lavallée, Y., Iddon, F. E., Hornby, A. J., Kendrick, J. E., von Aulock, F. W., \& Wadsworth, F. B. (2018). Disclosing the temperature of columnar jointing in lavas. Nature Communications, 9(1), 1-7.

Lan, H., Chen, J., \& Macciotta, R. (2019). Universal confined tensile strength of intact rock. Scientific Reports, 9(1), 1-9.

Lavallée, Y., Varley, N. R., Alatorre-Ibargüengoitia, M. A., Hess, K. U., Kueppers, U., Mueller, S., ... \& Dingwell, D. B. (2012). Magmatic architecture of dome-building eruptions at Volcán de Colima, Mexico. Bulletin of Volcanology, 74(1), 249-260.

Li, J., Zhang, G., \& Liu, M. (2019). Experimental investigation on the effect of confining pressure on the tensile strength of sandstone using hollow cylinder tensile test method. Arabian Journal of Geosciences, 12(24), 1-7.

Malik, A., Chakraborty, T., Rao, K. S., \& Kumar, D. (2017). Experiments to determine static and dynamic tensile strength of deccan trap rocks, India. Procedia Engineering, 191, 946953.

Manconi, A., Longpré, M. A., Walter, T. R., Troll, V. R., \& Hansteen, T. H. (2009). The effects of flank collapses on volcano plumbing systems. Geology, 37(12), 1099-1102.

Marmoni, G. M., Martino, S., Heap, M. J., \& Reuschlé, T. (2017). Gravitational slopedeformation of a resurgent caldera: New insights from the mechanical behaviour of Mt. Nuovo tuffs (Ischia Island, Italy). Journal of Volcanology and Geothermal Research, 345, $1-20$.

Martel, C., Dingwell, D. B., Spieler, O., Pichavant, M., \& Wilke, M. (2000). Fragmentation of foamed silicic melts: an experimental study. Earth and Planetary Science Letters, 178(12), 47-58.

Martel, C., Dingwell, D. B., Spieler, O., Pichavant, M., \& Wilke, M. (2001). Experimental fragmentation of crystal-and vesicle-bearing silicic melts. Bulletin of Volcanology, 63(6), 398-405.

Mayer, K., Scheu, B., Gilg, H. A., Heap, M. J., Kennedy, B. M., Lavallée, Y., ... \& Dingwell, D. B. (2015). Experimental constraints on phreatic eruption processes at Whakaari (White Island volcano). Journal of Volcanology and Geothermal Research, 302, 150-162.

Mayer, K., Scheu, B., Montanaro, C., Yilmaz, T. I., Isaia, R., Aßbichler, D., \& Dingwell, D. B. (2016). Hydrothermal alteration of surficial rocks at Solfatara (Campi Flegrei): Petrophysical properties and implications for phreatic eruption processes. Journal of Volcanology and Geothermal Research, 320, 128-143.

McBirney, A. R., \& Murase, T. (1970). Factors governing the formation of pyroclastic rocks. Bulletin Volcanologique, 34(2), 372-384. 
Montanaro, C., Scheu, B., Mayer, K., Orsi, G., Moretti, R., Isaia, R., \& Dingwell, D. B. (2016). Experimental investigations on the explosivity of steam-driven eruptions: A case study of Solfatara volcano (Campi Flegrei). Journal of Geophysical Research: Solid Earth, 121(11), 7996-8014.

Moon, K., \& Yang, S. B. (2020). Cohesion and Internal Friction Angle Estimated from Brazilian Tensile Strength and Unconfined Compressive Strength of Volcanic Rocks in Jeju Island. Journal of the Korean Geotechnical Society, 36(2), 17-28.

Mueller, S., Melnik, O., Spieler, O., Scheu, B., \& Dingwell, D. B. (2005). Permeability and degassing of dome lavas undergoing rapid decompression: an experimental determination. Bulletin of Volcanology, 67(6), 526-538.

Mueller, S., Scheu, B., Spieler, O., \& Dingwell, D. B. (2008). Permeability control on magma fragmentation. Geology, 36(5), 399-402.

Nara, Y., Hiroyoshi, N., Yoneda, T., \& Kaneko, K. (2010a). Effects of relative humidity and temperature on subcritical crack growth in igneous rock. International Journal of Rock Mechanics and Mining Sciences, 47(4), 640-646.

Nara, Y., Takada, M., Mori, D., Owada, H., Yoneda, T., \& Kaneko, K. (2010b). Subcritical crack growth and long-term strength in rock and cementitious material. International Journal of Fracture, 164(1), 57-71.

Perras, M. A., \& Diederichs, M. S. (2014). A review of the tensile strength of rock: concepts and testing. Geotechnical and Geological Engineering, 32(2), 525-546.

Richard, D., Scheu, B., Mueller, S. P., Spieler, O., \& Dingwell, D. B. (2013). Outgassing: Influence on speed of magma fragmentation. Journal of Geophysical Research: Solid Earth, 118(3), 862-877.

Rinne, H. (2008). The Weibull distribution: a handbook. CRC press.

Ryan, A. G., Heap, M. J., Russell, J. K., Kennedy, L. A., \& Clynne, M. A. (2020). Cyclic shear zone cataclasis and sintering during lava dome extrusion: Insights from Chaos Crags, Lassen Volcanic Center (USA). Journal of Volcanology and Geothermal Research, 401, 106935.

Sammis, C. G., \& Ashby, M. F. (1986). The failure of brittle porous solids under compressive stress states. Acta Metallurgica, 34(3), 511-526.

Scheu, B., Spieler, O., \& Dingwell, D. B. (2006). Dynamics of explosive volcanism at Unzen volcano: an experimental contribution. Bulletin of Volcanology, 69(2), 175-187.

Schultz, R. (1995). Limits on strength and deformation properties of jointed basaltic rock masses. Rock Mechanics and Rock Engineering, 28(1), 1-15.

Shea, T., Houghton, B. F., Gurioli, L., Cashman, K. V., Hammer, J. E., \& Hobden, B. J. (2010). Textural studies of vesicles in volcanic rocks: an integrated methodology. Journal of Volcanology and Geothermal Research, 190(3-4), 271-289.

Siratovich, P. A., von Aulock, F. W., Lavallée, Y., Cole, J. W., Kennedy, B. M., \& Villeneuve, M. C. (2015). Thermoelastic properties of the Rotokawa Andesite: a geothermal reservoir constraint. Journal of Volcanology and Geothermal Research, 301, 1-13.

Spieler, O., Kennedy, B., Kueppers, U., Dingwell, D. B., Scheu, B., \& Taddeucci, J. (2004). The fragmentation threshold of pyroclastic rocks. Earth and Planetary Science Letters, 226(1-2), 139-148.

Tang, C.-a. (1997). Numerical simulation of progressive rock failure and associated seismicity. International Journal of Rock Mechanics and Mining Sciences, 34(2), 249-261.

Tang, C.-a., Liu, H., Lee, P. K. K., Tsui, Y., \& Tham, L. (2000). Numerical studies of the influence of microstructure on rock failure in uniaxial compression-part I: effect of heterogeneity. International Journal of Rock Mechanics and Mining Sciences, 37(4), 555569. 
Tang, C.-a. \& Tang, S. (2011). Applications of rock failure process analysis (RFPA) method. Journal of Rock Mechanics and Geotechnical Engineering, 3(4), 352-372.

Tang, C.-a. \& Tang, S. (2020). Applications of Rock Failure Process Analysis (RFPA) to Rock Engineering. In Modelling Rock Fracturing Processes (pp. 421-459). Springer, Cham.

Troll, V. R., Hilton, D. R., Jolis, E. M., Chadwick, J. P., Blythe, L. S., Deegan, F. M., ... \& Zimmer, M. (2012). Crustal CO2 liberation during the 2006 eruption and earthquake events at Merapi volcano, Indonesia. Geophysical Research Letters, 39(11).

Tuffen, H., Dingwell, D. B., \& Pinkerton, H. (2003). Repeated fracture and healing of silicic magma generate flow banding and earthquakes? Geology, 31(12), 1089-1092.

Tuğrul, A., \& Gürpinar, O. (1997). A proposed weathering classification for basalts and their engineering properties (Turkey). Bulletin of Engineering Geology and the Environment, 55(1), 139-149.

Ündül, Ö., \& Er, S. (2017). Investigating the effects of micro-texture and geo-mechanical properties on the abrasiveness of volcanic rocks. Engineering Geology, 229, 85-94.

Varley, N., Connor, C. B., \& Komorowski, J. C. (Eds.). (2019). Volcán de Colima: Portrait of a Persistently Hazardous Volcano. Springer.

Vasseur, J., Wadsworth, F. B., Lavallée, Y., Hess, K. U., \& Dingwell, D. B. (2013). Volcanic sintering: timescales of viscous densification and strength recovery. Geophysical Research Letters, 40(21), 5658-5664.

Voltolini, M., Zandomeneghi, D., Mancini, L., \& Polacci, M. (2011). Texture analysis of volcanic rock samples: quantitative study of crystals and vesicles shape preferred orientation from X-ray microtomography data. Journal of Volcanology and Geothermal Research, 202(1-2), 83-95.

Wadsworth, F. B., Witcher, T., Vossen, C. E., Hess, K. U., Unwin, H. E., Scheu, B., ... \& Dingwell, D. B. (2018). Combined effusive-explosive silicic volcanism straddles the multiphase viscous-to-brittle transition. Nature Communications, 9(1), 1-8.

Walter, T. R., Harnett, C. E., Varley, N., Bracamontes, D. V., Salzer, J., Zorn, E. U., ... \& Thomas, M. E. (2019). Imaging the 2013 explosive crater excavation and new dome formation at Volcán de Colima with TerraSAR-X, time-lapse cameras and modelling. Journal of Volcanology and Geothermal Research, 369, 224-237.

Wedekind, W., López-Doncel, R., Dohrmann, R., Kocher, M., \& Siegesmund, S. (2013). Weathering of volcanic tuff rocks caused by moisture expansion. Environmental Earth Sciences, 69(4), 1203-1224.

Wiebe, R. A., Kolzenburg, S., Rooyakkers, S. M., \& Stix, J. (2021). Plutonic record of a caldera-forming silicic eruption: The shatter zone of the Cadillac Mountain granite, coastal Maine. Geosphere, 17(1), 1-22.

Wiesmaier, S., Heap, M. J., Branca, S., Gilg, H. A., Kueppers, U., Hess, K. U., ... \& Dingwell, D. B. (2015). Variability in composition and physical properties of the sedimentary basement of Mt Etna, Italy. Journal of volcanology and geothermal research, 302, 102116.

Wright, H. M., Cashman, K. V., Gottesfeld, E. H., \& Roberts, J. J. (2009). Pore structure of volcanic clasts: Measurements of permeability and electrical conductivity. Earth and Planetary Science Letters, 280(1-4), 93-104.

Wu, B., Yao, W., \& Xia, K. (2016). An experimental study of dynamic tensile failure of rocks subjected to hydrostatic confinement. Rock Mechanics and Rock Engineering, 49(10), 3855-3864.

Xu, T., Tang, C.-a., Zhao, J., Li, L., \& Heap, M. J. (2012). Modelling the time-dependent rheological behaviour of heterogeneous brittle rocks. Geophysical Journal International, 189(3), 1781-1796. 
Yasar, S., \& Komurlu, E. (2020). Water saturation induced changer in the indirect (Brazilian) tensile strength and the failure mode of some igneous rock materials. Geoscience Engineering, 66, 60-68.

Yavuz, A. B., Kaputoglu, S. A., Çolak, M., \& Tanyu, B. F. (2017). Durability assessments of rare green andesites widely used as building stones in Buca (Izmir), Turkey. Environmental earth sciences, 76(5), 211.

Yuan, Y., Xu, T., Heap, M. J., Meredith, P. G., Yang, T., \& Zhou, G. (2021). A threedimensional mesoscale model for progressive time-dependent deformation and fracturing of brittle rock with application to slope stability. Computers and Geotechnics, 135, 104160.

Zhan, Y., \& Gregg, P. M. (2019). How accurately can we model magma reservoir failure with uncertainties in host rock rheology? Journal of Geophysical Research: Solid Earth, 124(8), 8030-8042.

Zhang, Y. (1999). A criterion for the fragmentation of bubbly magma based on brittle failure theory. Nature, 402(6762), 648-650.

Zhou, G. L., Xu, T., Heap, M. J., Meredith, P. G., Mitchell, T. M., Sesnic, A. S. Y., \& Yuan, Y. (2020). A three-dimensional numerical meso-approach to modeling time-independent deformation and fracturing of brittle rocks. Computers and Geotechnics, 117, 103274.

Zhu, W. C., \& Tang, C.-a. (2006). Numerical simulation of Brazilian disk rock failure under static and dynamic loading. International Journal of Rock Mechanics and Mining Sciences, 43(2), 236-252.

Zhu, W. C., Bai, Y., Li, X. B., \& Niu, L. L. (2012). Numerical simulation on rock failure under combined static and dynamic loading during SHPB tests. International Journal of Impact Engineering, 49, 142-157.

Zhu, W., Baud, P., Vinciguerra, S., \& Wong, T. F. (2011). Micromechanics of brittle faulting and cataclastic flow in Alban Hills tuff. Journal of Geophysical Research: Solid Earth, 116(B6).

Zhu, W., Baud, P., Vinciguerra, S., \& Wong, T. F. (2016). Micromechanics of brittle faulting and cataclastic flow in Mount Etna basalt. Journal of Geophysical Research: Solid Earth, 121(6), 4268-4289.

Zorn, E. U., Rowe, M. C., Cronin, S. J., Ryan, A. G., Kennedy, L. A., \& Russell, J. K. (2018). Influence of porosity and groundmass crystallinity on dome rock strength: a case study from Mt. Taranaki, New Zealand. Bulletin of Volcanology, 80(4), 35. 